\title{
Review Article \\ Cytolethal Distending Toxin: A Unique Variation on the AB Toxin Paradigm
}

\author{
Joseph M. DiRienzo \\ Department of Microbiology, School of Dental Medicine, University of Pennsylvania, Philadelphia, PA 19104, USA \\ Correspondence should be addressed to Joseph M. DiRienzo; dirienzo@pobox.upenn.edu
}

Received 25 June 2014; Accepted 12 August 2014; Published 25 September 2014

Academic Editor: Alejandra Bravo

Copyright ( 2014 Joseph M. DiRienzo. This is an open access article distributed under the Creative Commons Attribution License, which permits unrestricted use, distribution, and reproduction in any medium, provided the original work is properly cited.

\begin{abstract}
Some of the most potent toxins produced by plants and bacteria are members of a large family known as the $A B$ toxins. $A B$ toxins are generally characterized by a heterogenous complex consisting of two protein chains arranged in various monomeric or polymeric configurations. The newest class within this superfamily is the cytolethal distending toxin (Cdt). The Cdt is represented by a subfamily of toxins produced by a group of taxonomically distinct Gram negative bacteria. Members of this subfamily have a related $\mathrm{AB}$-type chain or subunit configuration and properties distinctive to the $\mathrm{AB}$ paradigm. In this review, the unique structural and cytotoxic properties of the Cdt subfamily, target cell specificities, intoxication pathway, modes of action, and relationship to the $\mathrm{AB}$ toxin superfamily are compared and contrasted.
\end{abstract}

\section{Introduction}

Bacteria secrete a myriad of different types of proteins that exhibit a cell damaging or "cytotoxic" activity. Examples include but are not limited to membrane-damaging proteins such as RTX (repeats in toxin) and CDC (cholesteroldependent cytolysins), cell surface interacting proteins such as ST (heat-stable enterotoxins), and superantigens, as well as other proteins that attack cytosolic activities. One of the recurring organizational themes among secreted bacterial protein toxins that target intracellular processes in mammalian cells is a complex composed of at least two heterogeneous polypeptide chains or subunits. Each chain makes a distinct contribution to cell intoxication or toxic activity. The superfamily of cytotoxins that exhibit this structural arrangement have been generally labeled as the $A B$ toxins [1]. In this arrangement, the A chain or subunit typically functions as an enzyme that disrupts a specific cell process or pathway and the B chain or subunit, in monomeric or polymeric form, and promotes binding of the holotoxin to the target cell surface.

The newest member of the $\mathrm{AB}$ toxin superfamily, discovered by Johnson and Lior in 1987 [2], is the cytolethal distending toxin (Cdt). This toxin was named so because Chinese hamster ovary $(\mathrm{CHO})$ cells became stretched or enlarged when exposed to cell-free filtrates of enteropathogenic Escherichia coli (EPEC) isolated from young children diagnosed with gastroenteritis. Nucleotide sequences of the $E$. coli $c d t$ genes were first reported in 1994 by Pickett et al. [3] and Scott and Kaper [4] and revealed that the toxin was composed of three heterogenous subunits (CdtA, CdtB, and $\mathrm{CdtC}$ ). Publication of this sequence led to the rapid discovery of a family that represents a related subgroup of the $A B$ toxins. The various Cdts, like some of the other $\mathrm{AB}$ toxins, are produced by bacteria that are associated with specific diseases.

The objective of this treatise is to review current knowledge of the Cdt family and discuss how this subgroup compares and contrasts the $\mathrm{AB}$ toxin paradigm. Contributions from my laboratory are derived from studies of the $\mathrm{Cdt}$ produced by the human oral pathogen Aggregatibacter actinomycetemcomitans (formerly Actinobacillus actinomycetemcomitans) [5].

\section{AB-Type Toxins}

2.1. General Structural Features. Members of the AB toxin superfamily are presented in Table 1 . There are currently at least 17 confirmed members, and two additional potential 


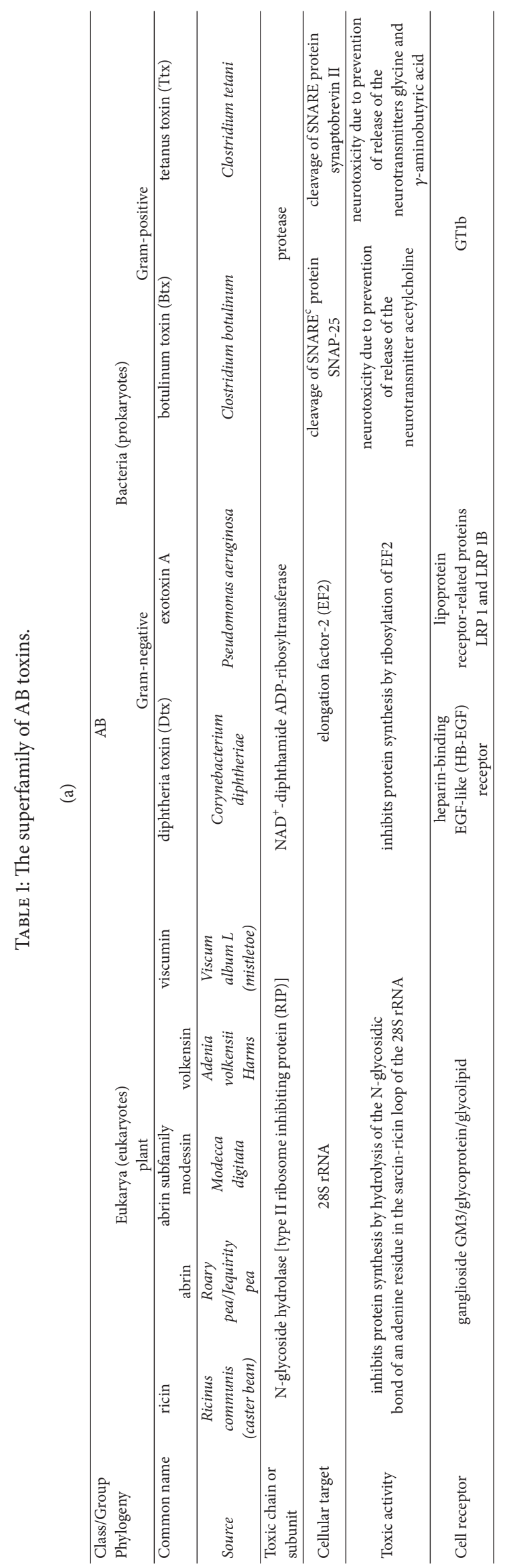




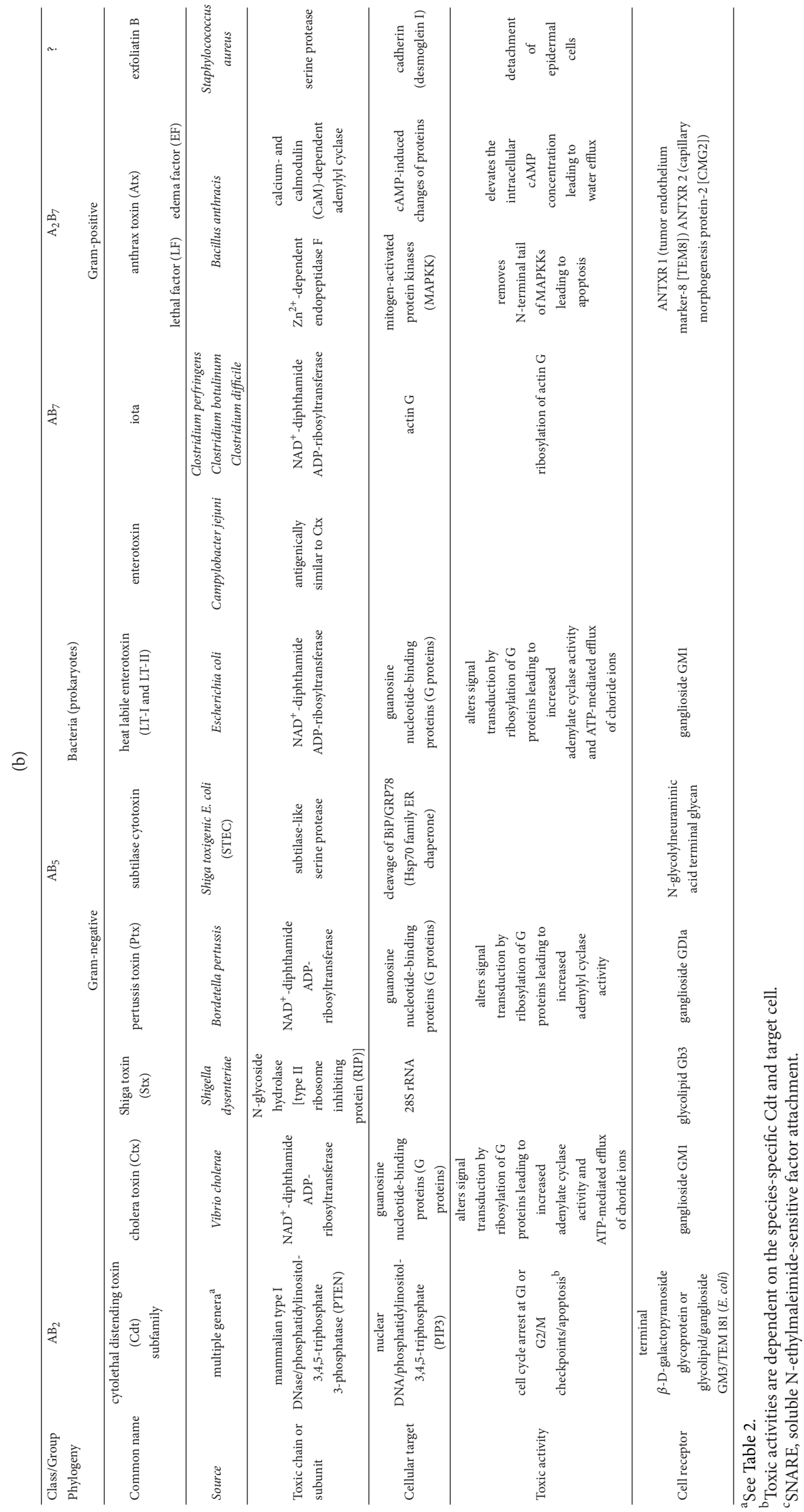




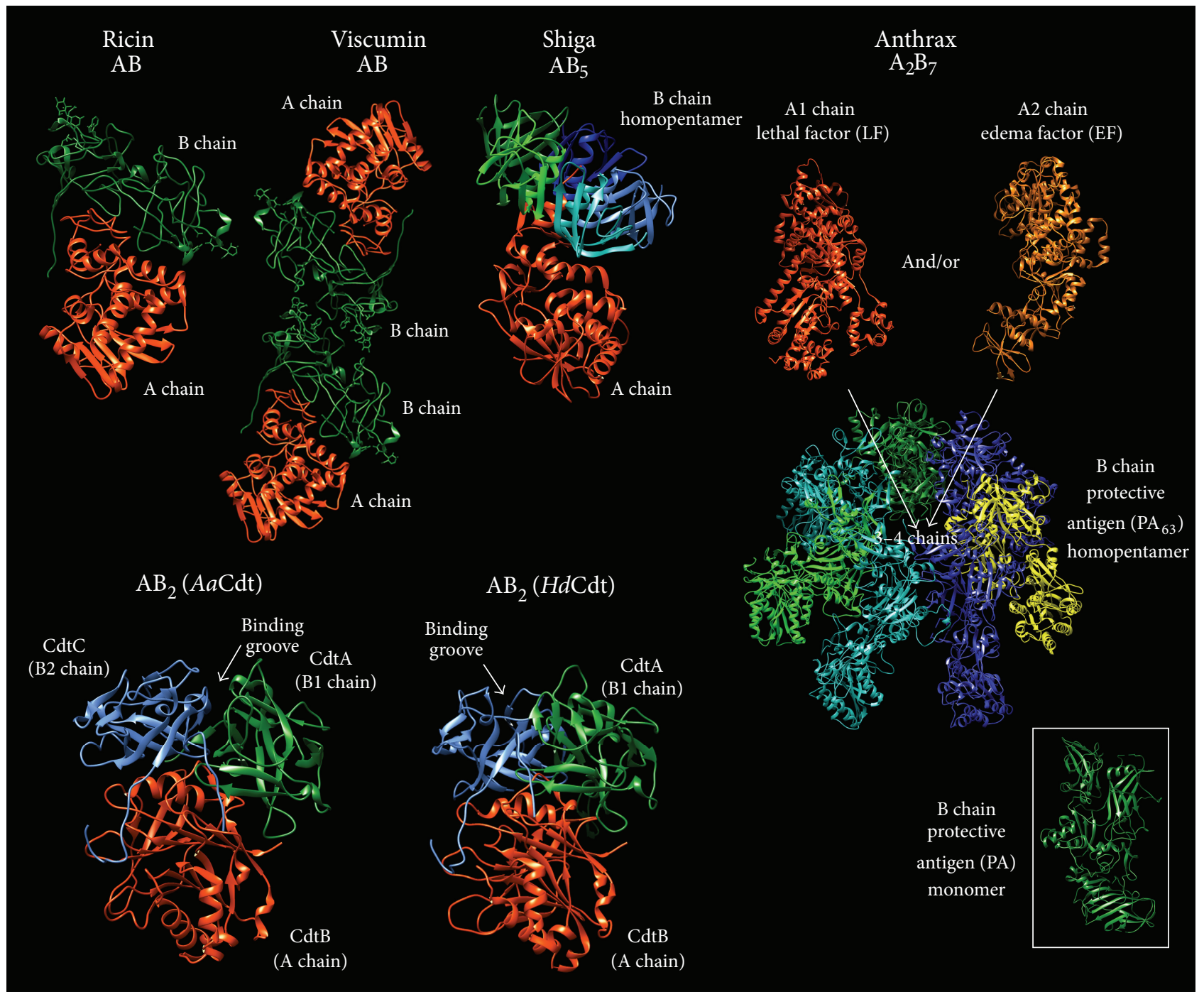

FIGURE 1: Structure comparisons of representative AB toxins. Structures of the A and B chains are shown as ribbon backbone models generated with UCSF Chimera 1.8.1. The anthrax B chain is depicted as the assembled heptamer. Three to four A1 or A2 chains or combinations of both chains are assembled in the holotoxin. The boxed structure shows the B chain monomer. Protein data bank (PDB) files: 2AAI (ricin and viscumin), 1R4Q (Shiga toxin), 1J7N (LF), 1XFY (EF), 1TZN (PA), 2F2F (AaCdt), and 1SR4 (HdCdt).

candidates (Campylobacter jejuni enterotoxin and exfoliatin B), which are distinguished by the specific arrangement of the $\mathrm{A}$ and $\mathrm{B}$ chains or subunits. For example, some $\mathrm{AB}$ toxins have a monomeric organization for both the $\mathrm{A}$ and $\mathrm{B}$ chains $(\mathrm{AB}$ class) while others contain one or two A chains and polymeric homo- or heterogeneous $\mathrm{B}$ chain complex $\left(\mathrm{AB}_{2}, \mathrm{AB}_{5}, \mathrm{AB}_{7}\right.$, and $\left.A_{2} B_{7}\right)$. Genes for all members of the $A B$ class identified to date are found in either specific species of plants or Grampositive or Gram-negative bacteria. Genes for the other classes $\left(\mathrm{AB}_{2-7}, \mathrm{~A}_{2} \mathrm{~B}_{7}\right)$ are found in either Gram-positive or Gram-negative bacterial species or, in some unusual cases, in the genome of bacteriophages [6] or on conjugative plasmids [7].

The A chains or toxic components of the holotoxin are represented by enzymes including an $\mathrm{N}$-glycosylase, $\mathrm{NAD}^{+}$-diphthamide ADP-ribosyltransferase, deoxyribonuclease/phosphatidylinositol-3,4,5-triphosphate 3-phosphatase
(PTEN, cation-dependent metalloenzyme), protein kinase, and $\mathrm{Zn}^{2+}$ metalloprotease. The most common terminal mode of action in susceptible cells is the disruption of protein biosynthesis. However, in a few examples, the A chain acts as a potent neurotoxin or genotoxin/cyclomodulin.

The $\mathrm{B}$ chain is required for the binding of the holotoxin to susceptible cells which is an essential step for internalization of the A chain. There is significantly greater heterogeneity in the composition and structure of the B chain most likely due to the fact that this component of the holotoxin has evolved to recognize a broad range of target cells. These differences are evident upon a comparison of the crystal structures of several representative examples of the $A B$ superfamily (Figure 1). Ricin, the most well-known representative of the $\mathrm{AB}$ class [8], is very similar to the other $\mathrm{AB}$ toxins of plant origin. The $\mathrm{A}$ and $\mathrm{B}$ chains are created by the cleavage of a single polypeptide chain. Following cleavage, the B chain 


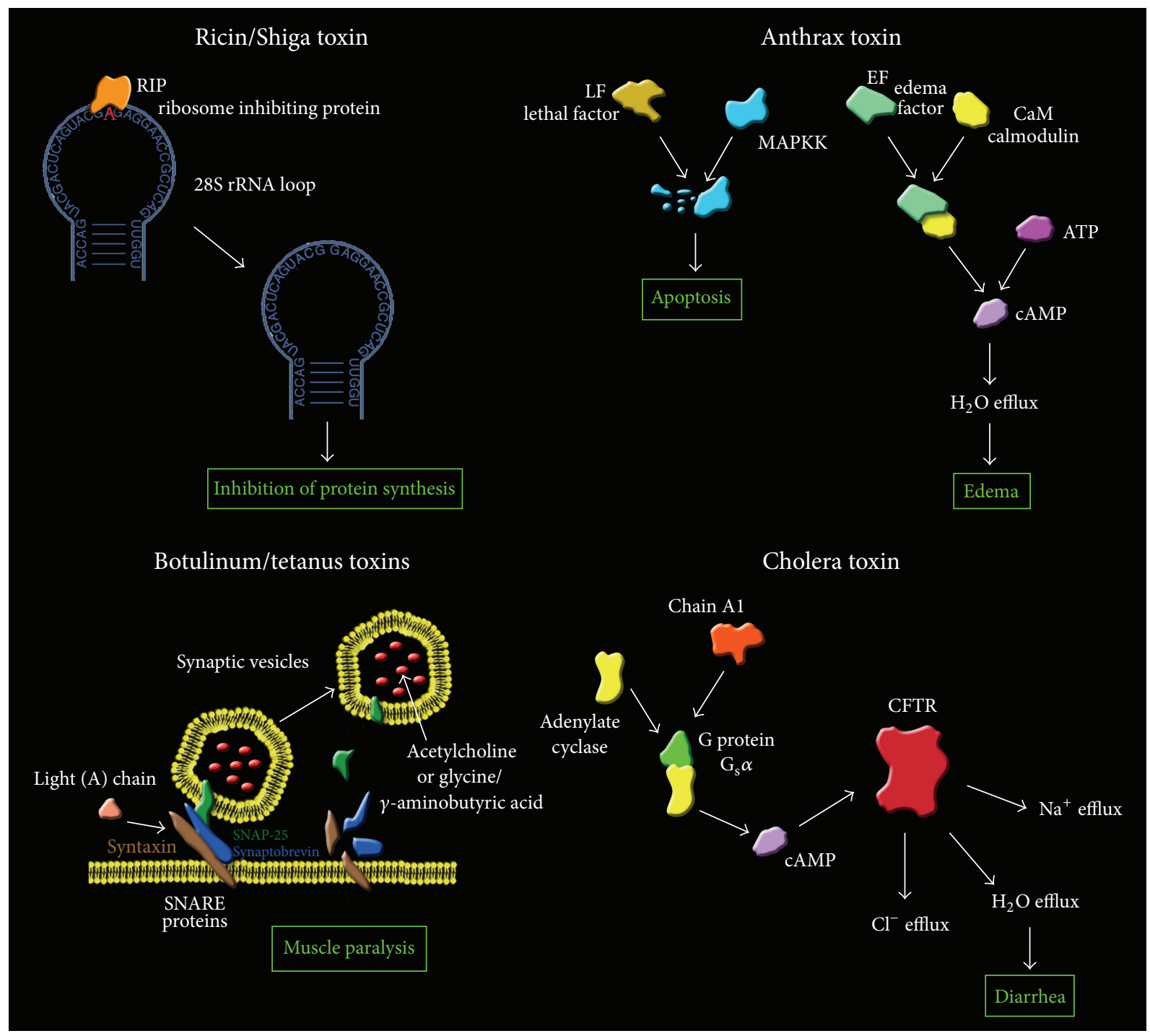

Figure 2: Comparison of the mode of action of the A chain of selected AB toxins. The A chain of ricin and Shiga toxin is a ribosomal inhibiting protein ( $\mathrm{N}$-glycoside hydrolase) that carries out a depurination by removing an adenine from the $28 \mathrm{~S}$ rRNA. The A chain of anthrax toxin is represented by two polypeptides known as the lethal factor (LF), a $\mathrm{Zn}^{2+}$-dependent endoprotease, and edema factor (EF), a polypeptide that forms a Ca ${ }^{2+}$ - and calmodulin-dependent adenylate cyclase. The A chain of cholera toxin is enzymatically cleaved to create a polypeptide (A1 chain) that ribosylates the guanosine nucleotide-binding protein $\mathrm{G}_{\mathrm{s}} \alpha$. The A chain of botulinum and tetanus toxins degrades specific soluble N-ethylmaleimide-sensitive factor attachment proteins (SNARE) which inhibits vesicle fusion and delivery of neurotransmitters such as acetylcholine. Additional details are provided in the text. MAPKK: mitogen-activated protein kinase kinases; CFTR: cystic fibrosis transmembrane conductance regulator.

becomes bound to the A chain (N-glycosylase) through a disulfide bridge $[9,10]$ and functions as a lectin that binds to terminal $\beta$-D-galactopyranoside residues on the cell receptor. In a slight variation on the ricin structure, the viscumin holotoxin forms a dimer, through a noncovalent linkage, to create an active toxin [11]. The B subunit of Shiga toxin is a homopentamer that binds to the membrane glycolipid globotriaosylceramide (Gb3), a gal- $\alpha(1-4)$-gal- $\beta(1-$ $4)$-glu trisaccharide linked to ceramide [12-14]. The B subunit of anthrax toxin is a heptamer of the polypeptide termed protective antigen (PA) which binds to the cell surface anthrax toxin receptors (ATR or ANTXR) $[15,16]$. Either one or both A chains, lethal factor (LF), and edema factor (ED) become attached as a 3-4 chain unit to the PA complex.

2.2. Modes of Action. Various A chain enzyme activities of AB toxins, other than those of the Cdt, result in the inhibition of protein synthesis, apoptosis, neurotoxicity, and alteration of cell signaling pathways (Figure 2).

2.2.1. Inhibition of Protein Synthesis. The A chain of all of the plant $\mathrm{AB}$ toxins and Shiga toxin is an N-glycosylase that removes adenine from the $28 \mathrm{~S}$ rRNA [17]. This depurination reaction completely inactivates the ribosome. Therefore, 
these toxins are known as an RIP (ribosome inhibiting protein). Diphtheria, cholera and pertussis toxins, exotoxin $\mathrm{A}$, and the heat-labile (LT) enterotoxins also disrupt protein synthesis. The A chain of these toxins is an ADPribosyltransferase. In diphtheria toxin and exotoxin $A$, the enzyme catalyzes the transfer of $\mathrm{NAD}^{+}$(nicotinamide adenine dinucleotide) to the elongation factor-2 (EF2). EF2, which is required for translocation of the nascent peptides on the polyribosomes, is inactivated resulting in the inhibition of RNA translation. The ADP-ribosyl transferases of the other toxins catalyze the transfer of different substrates.

2.2.2. Edema and Apoptosis. Anthrax toxin contains two heterogeneous A chains, known as the edema factor (EF) and lethal factor (LF) [16]. The EF forms a $\mathrm{Ca}^{2+}$ - and calmodulindependent adenylate cyclase that significantly increases the level of cAMP in the intoxicated cell. Calmodulin is a $\mathrm{Ca}^{2+}$ binding protein that modifies the interaction of this divalent cation with various other $\mathrm{Ca}^{2+}$-binding proteins. This action alters the water homeostasis of the cell and destabilizes intracellular signaling pathways which leads to high fluid accumulation in the tissues causing swelling. Macrophages are particularly susceptible to the toxin resulting in impaired immune function. The $\mathrm{LF}$ is a $\mathrm{Zn}^{2+}$-dependent endoprotease that cleaves the $\mathrm{N}$-terminal portion of the mitogen-activated protein kinase kinases (MAPKK). This action alters signaling pathways that require the intact kinases and contributes to apoptosis.

2.2.3. Ribosylation of $G$ Proteins. The A chain of cholera toxin is activated by a cleavage step. The enzymatically active Al fragment ribosylates the guanosine nucleotidebinding protein $G_{s} \alpha$. This reaction maintains the $G$ protein in a GTP-bound form that activates adenylate cyclase. As a consequence, high levels of cAMP are produced, activating the cystic fibrosis transmembrane conductance regulator (CFTR), resulting in excessive efflux of ions such as $\mathrm{Cl}^{-}$ and water from the intoxicated cells [18]. The high rate and volume of water released from epithelial cells (enterocytes) cause severe diarrhea.

2.2.4. Neurotoxicity. The A or light chain of the botulinum toxin functions as a protease that degrades the SNARE (soluble N-ethylmaleimide-sensitive factor attachment) protein SNAP-25 (synaptosomal-associated protein 25) [19]. The SNARE complex is a large superfamily of proteins, including syntaxin, synaptobrevin, synaptotagmin, and SNAP-25, required for normal vesicle fusion that controls exocytosis of cellular transport vesicles with the cell membrane. Vesicle fusion is the process by which neurotransmitters, such as acetylcholine, are released for the transmission of signals between neurons. Cleavage of the SNARE proteins disrupts vesicle fusion resulting in the inhibition of signal transmission leading to muscle paralysis. The activity of tetanus toxin is similar to that of botulinum toxin [20].

2.3. The Cdt Subfamily of AB Toxins. The Cdt is produced by a handful of facultative or microaerophilic Gram-negative bacteria that are key pathogens in diseases that involve the perturbation of a mucosal (enteritis, gastric ulcers, chancroid) or epithelial (periodontal diseases) layer (Table 2). According to convention, the species-specific Cdts are represented by an abbreviated genus and species prefix such as $A a C d t, ~[21]$. To date, eight species-specific Cdts have been confirmed. The EcCdt is represented by a subfamily in which the various members have the $c d t$ genes located on the chromosome, on plasmids or in bacteriophages. Five types of the $E c C d t$ have been identified based on nucleic acid sequence differences $[22,23]$. In comparison to the other classes of $A B$ toxins, the Cdt subgroup exhibits several unique properties:

(i) $c d t$ genes are carried and expressed by multiple genera of Gram-negative bacteria;

(ii) $c d t$ genes are most likely spread across genera and species by horizontal gene transfer;

(iii) the deduced amino acid sequences of all three subunits have phylogenetic relationships to eukaryotic proteins or polypeptides;

(iv) the Cdt complex contains two heterogeneous $\mathrm{A}$ subunits-CdtA and CdtC (equivalent to the B chain in other $\mathrm{AB}$ toxins);

(v) the CdtB subunit (equivalent to the A chain in other $\mathrm{AB}$ toxins) has the potential to exhibit multiple enzymatic activities and therefore affect different cell processes or pathways;

(vi) a major mode of action of the Cdt is that of a genotoxin since the toxin enters the nucleus of cells and damages the host DNA;

(vii) the Cdt indirectly affects regulation of the cell cycle thereby behaving as a cyclomodulin.

\section{Properties of the Cytolethal Distending Toxin}

3.1. Taxonomic Relationships among the Cdt. The $c d t$ operon, composed of a promoter and the three constitutively expressed structural genes, is usually found on the bacterial chromosome. However, it is likely that the operon was disseminated among the various Cdt-producing species by horizontal gene transfer. $C d t$ genes have been found in the genome of a bacteriophage from the aphid symbiont Hamiltonella defensa [6]. This gram-negative bacterium is related to the Enterobacteriaceae. Other E. coli bacteriophages also carry the $c d t$ genes $[24,25]$. These findings support the possibility of cross-species spread by transduction or transposition. It is interesting that the $c d t$ locus in some $E$. coli strains is flanked by lambdoid prophage genes [23] or is adjacent to a putative transposase gene as in Providencia alcalifaciens [26]. Cdt-like genes have also been identified on a virulence plasmid (pVir) isolated from a strain of $E$. coli obtained from a septicemic calf [7]. Taken together, these observations strongly support an extrachromosomal mechanism of gene dissemination across genus and species lines for the Cdt. 
TABLE 2: The cytolethal distending toxin subfamily of $A B$ toxins.

\begin{tabular}{|c|c|c|c|}
\hline Source $^{\mathrm{a}}$ & Habitat & $\begin{array}{l}\text { Associated affliction or } \\
\text { disease }^{b}\end{array}$ & Cell receptor \\
\hline \multicolumn{4}{|l|}{ Escherichia colic } \\
\hline Cdt-I (EPEC) & Lower intestine & Gastroenteritis & $\begin{array}{l}\text { Terminal } \\
\beta \text {-D-galactopyranoside } \\
\text { glycoprotein/TMEM181 }\end{array}$ \\
\hline Cdt-II (EPEC) & Lower intestine & Gastroenteritis & \\
\hline Cdt-III (septicemia) & Blood & Septicemia & \\
\hline Cdt-IV (pVir) & Lower intestine & $\begin{array}{l}\text { Gastroenteritis/urinary } \\
\text { tract infection }\end{array}$ & \\
\hline Cdt-V (STEC) & Lower intestine & Gastroenteritis & \\
\hline Campylobacter sp. & Lower intestine & Gastroenteritis & Unknown \\
\hline $\begin{array}{l}\text { Salmonella enterica subsp. enterica } \\
\text { serovar Typhi }\end{array}$ & Lower intestine & Typhoid fever & Unknown \\
\hline Shigella dysenteriae/Shigella boydii & Lower intestine & Dysentery & Unknown \\
\hline Providencia alcalifaciens & Lower intestine & Gastroenteritis & Unknown \\
\hline Helicobacter sp. & Stomach/liver & $\begin{array}{l}\text { Duodenal ulcers/stomach } \\
\text { cancer/chronic hepatitis }\end{array}$ & Unknown \\
\hline Haemophilus ducreyi & Genitalia & Chancroid & Unknown \\
\hline $\begin{array}{l}\text { Aggregatibacter } \\
\text { actinomycetemcomitans }\end{array}$ & Oral cavity & $\begin{array}{l}\text { Localized aggressive and } \\
\text { possibly chronic } \\
\text { periodontitis/infectious } \\
\text { endocarditis }\end{array}$ & $\begin{array}{l}\text { GM3 (also possibly GM1 } \\
\text { and GM2) }\end{array}$ \\
\hline bacteriophage & $\begin{array}{l}\text { Hamiltonella } \\
\text { defensa }\end{array}$ & Aphid symbiont & Not applicable \\
\hline
\end{tabular}

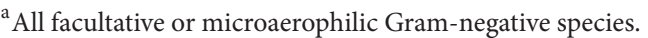

${ }^{\mathrm{b}}$ All diseases involving a mucosal or epithelial layer.

${ }^{c}$ EPEC: enteropathogenic E. coli; STEC: Shiga toxigenic E. coli; pVir: conjugative E. coli plasmid.
}

Deduced amino acid sequence comparisons indicated that the Aacdt locus may reside in an extant genomic or pathogenicity island (GIY4-1) marked by a bacteriophage attachment (att) sequence and the integrase/resolvase gene $(x e r D)$. This putative genomic island may have been passed in succession from Haemophilus somnus to $H$. influenzae to H. ducreyi to A. actinomycetemcomitans [27]. More recently, the Aacdt operon has been found on a genomic island ( $c d t$ island) distinct from GIY4-1 [28]. The $2.5 \mathrm{~kb} c d t$ operon and $1.3 \mathrm{~kb}$ region immediately upstream are the only regions of sequence homology between GIY4-1 and $c d t$-island. These findings suggest that the $c d t$ genes may have been acquired by A. actinomycetemcomitans as a result of at least two unrelated recombinational events. The $\% \mathrm{G}+\mathrm{C}$ content of the Aacdt gene sequences indicate that they are foreign to this bacterial species. However, the deduced amino acid sequences [29] are over $90 \%$ similar to those from $H$. ducreyi [30]. This relationship is expected since A. actinomycetemcomitans and Haemophilus sp. are closely related members of the taxonomic family Pasteurellaceae [28]. The distribution of the $c d t$ genes among taxonomically unrelated Gram-negative genera such as the Enterobacteriaceae and Pasteurellaceae fits a model of spread by horizontal gene transfer. It is curious that genes for the other classes of bacterial $A B$ toxins do not appear to have crossed species lines. However, there are similarities among the $\mathrm{A}$ chains of toxins produced by several different bacterial genera. For example, an ADPribosyltransferase is present in toxins produced by some strains of E. coli, Corynebacterium diphtheriae, Pseudomonas aeruginosa, Vibrio cholera, Bordetella pertussis, and Clostridium sp. (see Table 1). However, the cytotoxic end-points are different.

In spite of the evidence for genomic plasticity, there is no obvious selective pressure on the $\mathrm{A} a \mathrm{Cdt}$-producing species to prevent shedding and maintain expression of the $c d t$ genes. Indeed, fresh clinical isolates of $\mathrm{AaCdt}$-producing strains do not appear to readily lose expression of the $c d t$ genes after extensive laboratory cultivation. In contrast, the shedding of nonessential genes is readily apparent as in the case of the tad (tight adherence) locus of A. actinomycetemcomitans [31]. All clinical isolates of this bacterium start out with an adherent "rough" colony morphology or phenotype that is rapidly lost, resulting in a nonadherent "smooth" phenotype, upon repeated subculturing in the laboratory. It has been proposed that prokaryotic genomes, especially those of pathogens, remain relatively small and generally lack nonfunctional sequences even though they are continuously evolving by acquiring genes due to horizontal gene transfer [32-35]. This contradiction can be explained by a concept known as deletional bias in which genetic change is skewed towards deletions rather than insertions. Interaction of a bacterium with a host leads to low genetic diversity and 


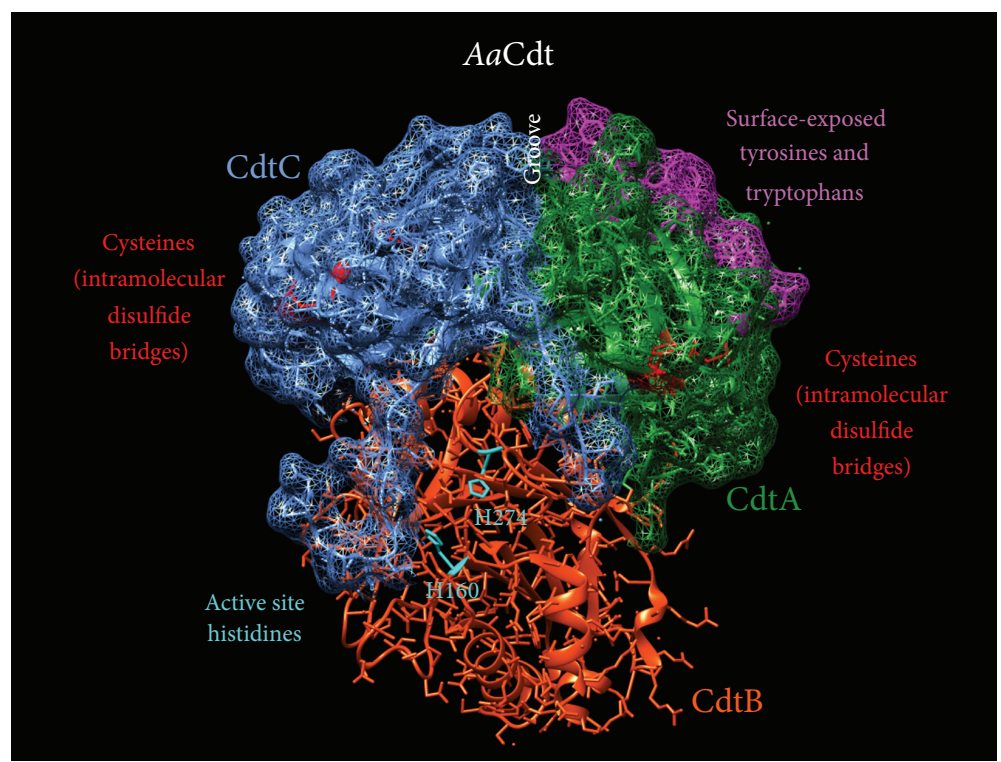

FIgure 3: Organization of the CdtA, CdtB, and CdtC subunits in the AaCdt holotoxin. The computer model was generated with UCSF Chimera 1.8.1 using the PDB file 2F2F. CdtA and CdtC are shown as surface mesh models. Surface-exposed heterocyclic amino acid residues in the aromatic patch are shown in magenta. A putative receptor binding groove is formed between CdtA and CdtC. Cysteines in CdtA and $\mathrm{CdtC}$ are in red and form two putative internal disulfide bridges in CdtA and CdtC. CdtB is depicted as a ribbon structure. The two histidine residues (H160 and $\mathrm{H} 274$ ) in the active site are required for nuclease and phosphatidylinositol-3,4,5-triphosphate 3-phosphatase activities and are shown in cyan. All three subunits are held together by noncovalent forces.

infrequent recombination [36, 37]. Calculated gene loss rates indicate that genome size can be extensively reduced during a relatively short evolutionary time period [33]. Therefore, there must be an essential, or at least a highly important, purpose for $c d t$ gene expression in A. actinomycetemcomitans or these genes would be lost over time.

3.2. Regulation of the $c d t$ Operon. The $c d t$ genes are expressed from a polycistronic operon and are well conserved among the $\mathrm{Cdt}^{+}$species [38-40]. The operon typically consists of a promoter and the three structural genes CdtA, CdtB, and CdtC. It has been reported that in some strains of $A$. actinomycetemcomitans two small open reading frames, orf1 (263 bp) and orf2 (258 bp) immediately upstream of $c d t A$, are cotranscribed in vitro with the three structural genes [41]. It does not appear that expression of orf1 and orf 2 is essential for Cdt functions but may possibly have regulatory roles in transcription. In a rare finding, introns or intervening sequences have been located in the Aacdt transcript [42]. Introns, when present in prokaryotic cells, are usually present in genes that function in the transfer of conjugative transposons or recombination. Their presence in the $c d t$ transcript may be a phylogenetic holdover from its relationship to the plant (eukaryotic) members of the $\mathrm{AB}$ family and may represent a mechanism for transcriptional control. Aggregatibacter actinomycetemcomitans is a facultative bacterium and it has been reported that $c d t B$ gene expression was upregulated 2 -fold in stationary phase during anaerobic growth [43]. Bacteria such as A. actinomycetemcomitans associated with periodontal diseases colonize sites of relatively low oxygen tension in the human oral cavity $[44,45]$.
3.3. Holotoxin Structure. Biologically active Cdt is a trimer having the $\mathrm{AB}_{2}$ configuration (Figure 3 ). This holotoxin configuration is consistent in all Cdt-producing species examined to date except for that in Salmonella enterica serovar Typhi [21] which lacks the $c d t A$ and $c d t C$ genes [46]. Deduced amino acid sequence comparisons among representative species-specific Cdts reveal as much as $45 \%$ sequence identity between the most distantly related CdtB subunits $[25,47$, 48]. CdtA sequence identities range between 93 and 26\% and $\mathrm{CdtC}$ sequence identities range between 95 and 19\%. In spite of this diversity, there appears to be a commonality of function among the species-specific Cdt subunits. Similar function in the case of significant sequence diversity is not uncommon based on studies of "highly divergent proteins." A good example is triosephosphate isomerase (TIM) which functions in glycolysis and is therefore found throughout the universal phylogenic tree [49]. TIM amino acid sequences are highly divergent. For example, the E. coli and Pseudomonas aeruginosa TIMs differ in 120 of 255 residues. In spite of this high divergence, TIM structures are very well conserved, being nearly identical, as illustrated by superimposing the structures of the E. coli and chicken TIM proteins [50]. It is not surprising that the Cdt proteins are highly divergent since they most likely have been disseminated among species by horizontal gene transfer which, as a consequence, results in a relatively high frequency of genetic change.

3.3.1. B Chain Activity. The "B chain" of the Cdt is a heterodimer composed of the products of the $c d t A$ and $c d t C$ genes. The mature $\mathrm{CdtA}$ and $\mathrm{CdtC}$ proteins are made up of, on average, 220 and 165 amino acids, respectively. Both CdtA and $\mathrm{CdtC}$ contain four cysteines that have the potential to 
form two intramolecular disulfide bridges $[48,51]$. There is no evidence of disulfide bond formation between the subunits based on the location of the cysteine resides in the CdtA and CdtC structures (see Figure 3).

It was predicted from the crystal structure of the $\mathrm{HdCdt}$ that $\mathrm{CdtA}$ and $\mathrm{CdtC}$ form a ricin-like lectin binding domain composed of a deep groove, between the two subunits, and a region of aromatic and heterocyclic amino acids exposed on the surface of CdtA [52]. The same features are evident in the crystal structure of the $\mathrm{AaCdt}$ [53]. However, it is predicted that the $\mathrm{AaCdt}$ holotoxin, unlike the $\mathrm{HdCdt}$, forms a dimer due to differences in the amino acid composition of a nonconserved loop in CdtB. There is functional similarity between a sequence of 60-88 amino acids in CdtA and the $B$ chain of the ricin/abrin toxin subfamily based on amino acid sequence threading analysis [54] and a reverse position specific- (RPS-) BLAST search of the conserved domain (CD) database [39]. The ricin B chain differs from CdtA such that it was formed by a series of gene duplications that created two sugar-binding domains. Each domain is made up of three copies of a 40 residue galactose-binding peptide [10]. An interesting parallel relationship between the binding properties of the ricin $\mathrm{B}$ chain and CdtA is evident from experiments performed using the $E c \mathrm{Cdt}$. It was observed that the binding of CdtA and CdtC to the surface of HeLa cells could be blocked with glycoproteins that specifically contain $\mathrm{N}$-linked fucose moieties [55]. My laboratory took advantage of this in vitro binding specificity to use a modified enzymelinked immunosorbent assay (ELISA), with thyroglobulincoated plastic plates to study the binding kinetics of wildtype and mutated $A a C d t A$ and $A a C d t C$ subunits [56]. We found that $\mathrm{CdtA}$ alone bound with saturation kinetics to thyroglobulin. CdtC also bound to thyroglobulin, but at a much lower ratio of ligand to receptor. Using a series of glycandeficient $\mathrm{CHO}$ cell mutants [57], Eshraghi et al. [58] were unable to confirm a role for $\mathrm{N}$-linked glycans and glycolipids in the binding of either $E c \mathrm{Cdt}$ or $A a \mathrm{Cdt}$. However, binding studies employing the thyroglobulin assay to examine the effect of single amino acid substitutions in CdtA empirically confirmed that surface-exposed heterocyclic amino acids in the "aromatic patch" region and on the CdtA face of the heterodimer groove [52] were essential for Cdt binding [59]. $\mathrm{Li}$ et al. [60] subsequently found that a heterocyclic amino acid (W115) that resides outside of the aromatic patch is also critical for receptor binding.

We found that $\mathrm{CdtC}$ binds poorly to $\mathrm{CHO}$ cells and does not enhance the binding of CdtA [56, 59]. These results suggested to us that the CdtA subunit may have a significantly greater role than $\mathrm{CdtC}$ in toxin binding in vivo. The results of binding studies based on immunofluorescence $[39,55,61]$ and an enzyme-linked immunosorbent assay on live cells (CELISA) $[56,62]$ reinforced our hypothesis. Other studies have shown that $\mathrm{CdtC}$ can bind to HeLa and HEp-2 cells in culture and in a CELISA $[55,62,63]$. The presence of an obvious groove in the CdtA-CdtC heterodimer structure and some amino acid sequence similarity between regions in the two subunits $[59,62]$ suggests, but does not confirm, that the two subunits may work cooperatively such that CdtC facilitates binding of CdtA.
In contrast to the glycoprotein data, the individual $A a C d t$ subunits were tested for binding to gangliosides Gal $\beta(1,3)$ GalNAc $\beta(1,4)$ NeuAc $\alpha(2,3)$-Gal $\beta(1,4)$ Glc-ceramide (GM1), GalNAc $\beta(1,4) \mathrm{NeuAc} \alpha(2,3)$-Gal $\beta(1,4)$ Glc-ceramide (GM2), NeuAc $\alpha(2,3) \mathrm{Gal} \beta(1,4)$ Glc-ceramide (GM3), Gal $\alpha(1-$ 4) Gal $\beta(1-4)$ Glc-ceramide (Gb3), and GalNAc- $\beta(1-3)$ Gal- $\alpha(1-$ 3) Gal- $\beta(1-4)$ Glc-ceramide (Gb4) [64]. AaCdtA and AaCdtC bound primarily to GM1 and GM2. However, GM3 exhibited the greatest inhibition of Cdt-induced toxicity in the human monocyte cell line U937. Gangliosides such as GM1, GM3, and $\mathrm{Gb} 3$ have been implicated as receptors for other $\mathrm{AB}$ toxins such as ricin [65], LT-I/LT-II [66], cholera toxin [67], and Shiga toxin [68]. Interestingly, GM3 is a component of membrane lipid rafts [69]. Lipid rafts are membrane domains enriched in glycosphingolipids and cholesterol and have been implicated as the binding site in $\mathrm{AaCdt}$-mediated cell cycle arrest of Jurkat cells, a T-cell leukemic cell line [70, 71]. Those studies implied that CdtC-mediated binding to lipid rafts, via a cholesterol recognition/interaction amino acid consensus (CRAC) sequence (LIDYKGK) within the protein, is important for Cdt uptake.

The G-protein-coupled receptor, TMEM181, has been identified as a third potential Cdt cell receptor [72]. This membrane protein was implicated in the binding of the $E c C d t$ using a novel haploid genetic screening method in a derivative of a chronic myeloid leukemia cell line.

The identity of the Cdt receptor(s) has been a challenging problem. Based on the structural analyses and in vitro binding kinetics, it seems apparent that a CdtA$\mathrm{CdtC}$ heterodimer carries out the $\mathrm{B}$ chain function of other classes of $A B$ toxins. However, more information is needed to establish the precise role of each subunit in the attachment of the Cdt to susceptible cells. One complication is that evidence is accumulating to support the idea that the species-specific Cdts, or subgroups such as Aggregatibacter/Haemophilus (Pasteurellaceae subgroup) and Escherichia/Salmonella/Campylobacter/Helicobacter (GI subgroup), may have distinct host cell receptors or that multiple receptors exist in specific cells or cell lines. Based on intoxication experiments using wild-type $\mathrm{CHO}$ cells treated with tunicamycin or loaded with cholesterol and $\mathrm{CHO}$ cell mutants containing a sialic acid galactose transporter or glycolipid deficiency, the species-specific Cdts separated into three subgroups, $A a \mathrm{Cdt} / \mathrm{HdCdt}, E c \mathrm{Cdt}$, and $C j \mathrm{Cdt}$, requiring different host cell properties [58]. As noted by this group of investigators, the precise molecular conformation and presentation of the Cdt receptor on the cell surface may be essential to obtain Cdt binding. The implications of these observations mean that binding to a native receptor may only be observable with intact cells since purification of the receptor may significantly alter the conformation required for correct interaction with the toxin.

3.3.2. A Chain Activity. The biologically active or toxic component of the $\mathrm{Cdt}$, comparable to the A chain of the other classes of $\mathrm{AB}$ toxins, is also an enzyme. Based on a position-specific iterated (PSI) BLAST analysis [73], $E c \mathrm{CdtB}$ and $\mathrm{CjCdtB}$ matched to type I deoxyribonucleases 
$[74,75]$. However, a broader deduced amino acid sequence comparison showed that CdtB belongs to a superfamily of enzymes that includes the endonucleases, exonucleases, sphingomyelinases, and inositol polyphosphate 5-phosphatases [76]. The phylogenetic relationships imply that CdtB appears to be most closely related to prokaryotic and bacteriophage deoxyribonuclease I and sphingomyelinase $\mathrm{C}$ with broader similarities to PTEN and eukaryotic deoxyribonuclease I. Therefore, CdtB has the potential to exhibit multiple enzymatic activities in vitro and in vivo.

(1) Deoxyribonuclease-Like Activity. Recombinant CdtB exhibits nicking or relaxation activities, in vitro, when incubated with supercoiled DNA [74]. DNA damage in the form of double-strand breaks, as assessed by pulsed-field gel electrophoresis (PFGE), has also been observed in sensitive cell types exposed to the heterotrimer [61, 77, 78]. CdtB requires divalent cations for DNA-nicking activity [74, 79] with an optimum concentration of $50 \mathrm{mM} \mathrm{MgCl}_{2}, \mathrm{CaCl}_{2}$, or $\mathrm{MnCl}_{2}$ for the $\mathrm{AaCdtB}$ [80]. Mutating the conserved deoxyribonuclease active site residues His160 and His274 in the $\mathrm{HdCdt}$ [48], or their equivalent His residues in the other species-specific CdtBs, results in the loss of both in vitro nuclease activity and cell cycle arrest [74, 75]. Chimeric proteins composed of the amino terminal half of the $A a \mathrm{Cdt}$ and the carboxy terminal half of human deoxyribonuclease I (CdtB/DNaseI) exhibited DNA-nicking activity, in vitro, comparable to that of $\mathrm{CdtB}$, and formed an active heterotrimer complex with $\mathrm{CdtA}$ and $\mathrm{CdtC}$ [80]. The reverse chimeric construct, DNaseI/CdtB, also retained DNA-nicking activity but failed to form an active heterotrimer. Therefore, it appears that a primary activity of $\mathrm{CdtB}$ is to act as a neutral, cation-dependent deoxyribonuclease I-like nuclease $[61,74]$. Pulsed-field gel electrophoresis of HeLa and immortalized labial epithelial cells (GMSM-K) exposed to the AaCdt [61] and HeLa cells treated with the HdCdt [78] showed that the toxin causes DNA double-strand breaks in vivo. The induction of DNA double-strand breaks occurs by 6 hours after intoxication and leads to the formation of actin stress fibers by way of an ATM-dependent activation of the small GTPase, RhoA [81, 82]. This DNA-damaging activity is unusual for an $\mathrm{AB}$ toxin and supports the in vivo activity of the Cdt as a genotoxin [83]. The EcCdt induces DNA double-strand breaks primarily in the S phase of HeLa cells that are exposed to a low dosage of the toxin [84]. Singlestrand breaks were converted to double-strand breaks during the $S$ phase and the cells attempted to repair the damage by homologous recombination. These data indicate that the $S$ phase may play a more important role in the toxicity of the Cdt in some cell types and have important implications for cells that are deficient in homologous recombination. The other members of the AB toxin superfamily do not target host cell DNA. One exception, Shiga toxin has been reported to damage single-stranded DNA [85]. However, the damage caused by this toxin is due to depurination rather than cleavage of phosphodiester linkages.

(2) Consequences of DNA Damage. DNA damage results in the recruitment of protein complexes for DNA repair and leads to growth arrest at specific "checkpoints" in the cell cycle. When DNA damage is detected by cells, the goal is to prevent DNA replication and mitosis. The cell cycle checkpoints block progression from the $G_{1}$ to the $S$ phase or from the $G_{2}$ to the $\mathrm{M}$ phase (Figure 4(a)). Cell cycle arrest at these checkpoints can be detected and quantified by flow cytometry using fluorescence-activated cell sorting (FACS). A population of cells having a $2 n$ DNA content indicative of cells in the $\mathrm{G}_{1}$ phase can be separated from that having a $4 n$ DNA content. Thus, quantitative detection of the accumulated cells having an increased DNA content is indicative of $\mathrm{G}_{2}$ arrest (Figure 4(b)).

During normal growth, the protein kinases Mytl and Weel phosphorylate the effector kinase Cdc2/Cdk1 at positions Thr14 and Tyr15, respectively (Figure 3(c)). The phosphorylated Cdc 2 forms a complex with cyclin B. This complex is required for the cells to enter mitosis and is activated by the removal of the phosphates from Thr14 and Tyr15 by the protein phosphatase Cdc25. Once the cells enter mitosis, the cyclin B is degraded and Cdc2 is recycled by dephosphorylation of Thr161.

The pathways for cell cycle arrest in response to the Cdt appear to be cell-type specific and have been presented in various reviews [86-91]. Cdt-induced DNA damage can trigger pathways leading to the inhibition of cell proliferation, cell death, detrimental changes in cell morphology or alterations in cell signaling. In human cells, when DNA damage occurs, the sensor proteins Mrell, Rad50, Rpal3 , and Nbs1 (MRN complex) are recruited to the site [92, 93]. Depending on the cell-type various checkpoints, DNA repair and/or signaling pathways are initiated (Figure 4(d)). Arrest at the $G_{1}$ phase of the cell cycle has been reported in primary lung fibroblasts after exposure to the HdCdt [94, 95] and in the human fetal lung fibroblast cell line IMR90 following treatment with the CjCdt [96]. The classical $\mathrm{G}_{1}$ arrest pathway initiated by DNA damage occurs when a phosphorylated p53 (tumor suppressor protein) complex mediates the upregulation of p21. The p21 inactivates a Cdc2cyclin E complex that prevents the cells from progressing to the $S$ phase and also binds to PCNA (proliferating cell nuclear antigen) which results in an inhibition of DNA replication [97]. AaCdt-induced expression of p21 may drive $\mathrm{G}_{2}$ arrest in B cells [98] and p53-dependent and independent pathways may regulate the transition from $G_{2}$ to $M$ phase under genotoxic stress [99].

Human foreskin fibroblasts exposed to the $\mathrm{HdCdt}$ arrested at both the $G_{1}$ and $G_{2}$ phases [94]. Similar results were obtained with HPLF and HGF treated with a Cdt-containing extract from $A$. actinomycetemcomitans and recombinant $H d C d t$ [100]. Indeed, it appears that the response of most Cdt-sensitive cell types is cell cycle arrest at the $\mathrm{G}_{2} / \mathrm{M}$ interphase $[7,75,91,94,95,100-110]$. As in the case of $\mathrm{G}_{1}$ arrest, Cdt-induced DNA damage triggers a response by the sensor proteins leading to activation of the ATM (ataxia telangiectasia mutated) and ATR (ATM and Rad3-related) checkpoint pathways [111]. In these pathways, the effector kinases Chk1 and Chk2 phosphorylate Cdc25 at Ser216. This inactive form, phospho-Cdc25, fails to dephosphorylate the checkpoint protein kinase $\mathrm{Cdc} 2(\mathrm{Cdk} 1)$ that is complexed 


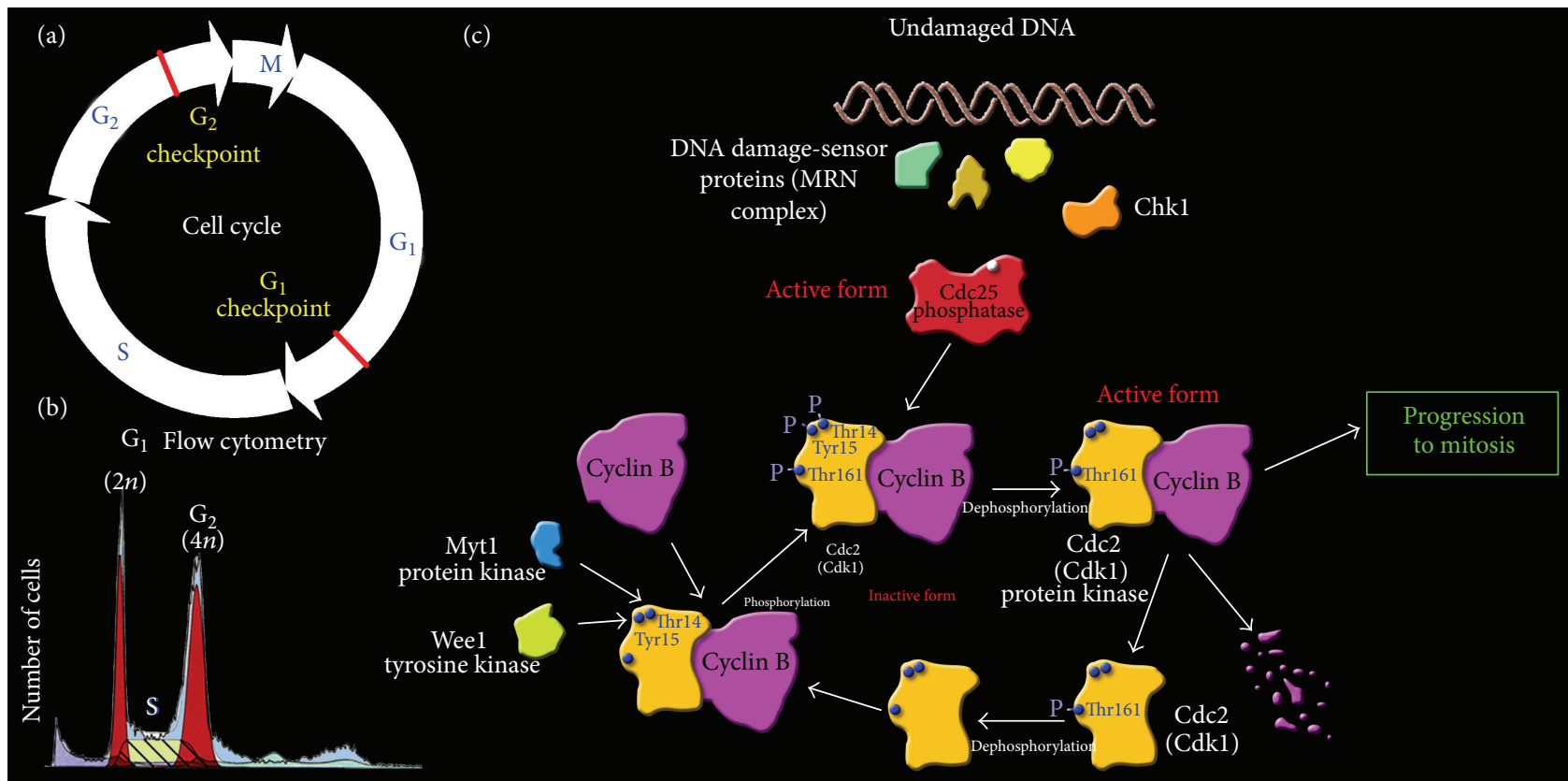

Amount of DNA per cell

(d)

(e) CdtB-altered cell signaling

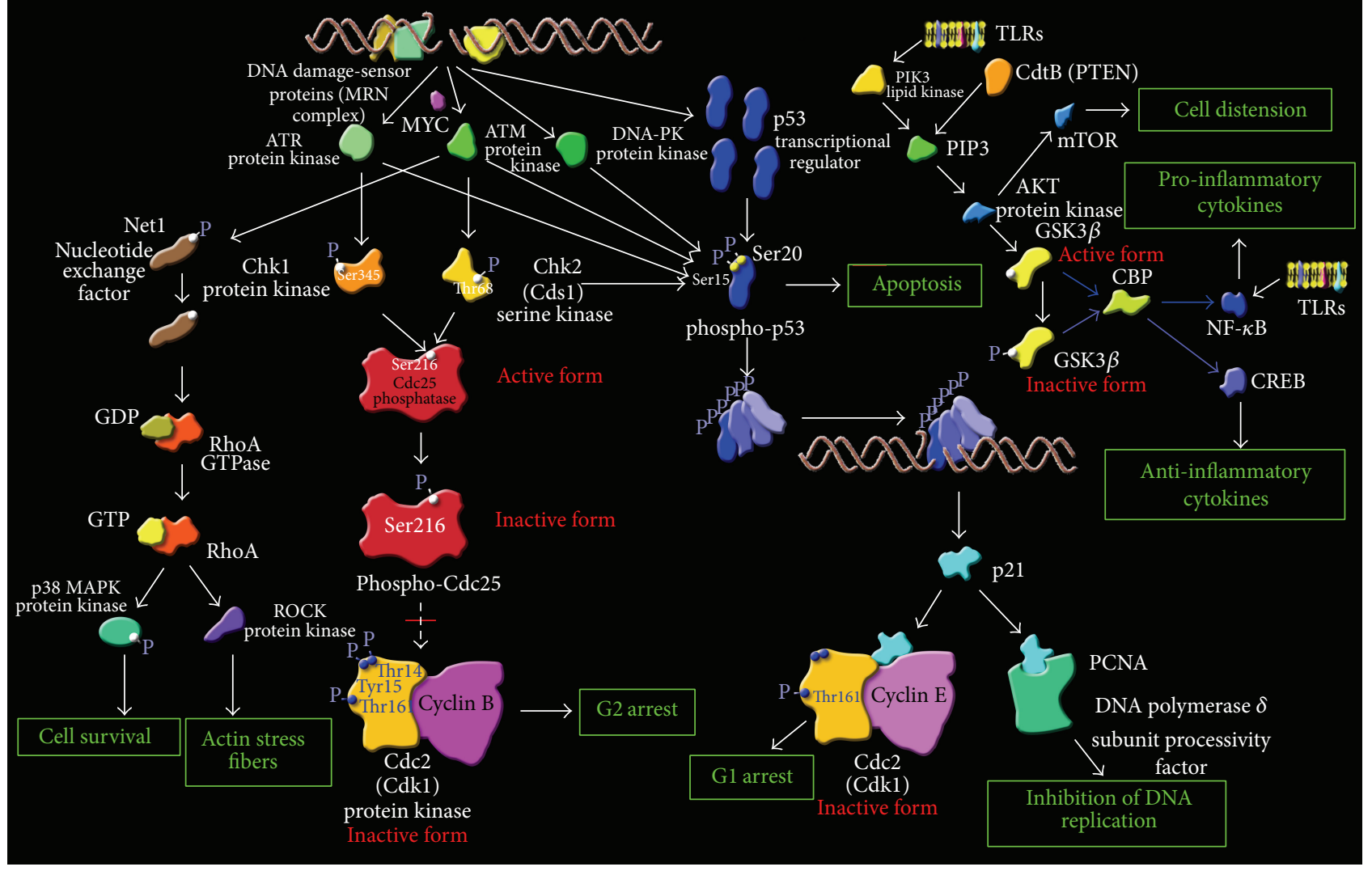

FIGURE 4: CdtB-induced inhibitory pathways. (a) Schematic representation of stages in the cell cycle showing the locations of the $\mathrm{G}_{1}$ and $G_{2}$ DNA damage checkpoints. (b) Cell cycle arrest at $G_{2} / M$ can be measured by flow cytometry or cell sorting. Populations that are arrested at $\mathrm{G}_{2} / \mathrm{M}$ accumulate cells that have a $4 n$ DNA content. (c) Normal cell cycle pathway leading to mitosis. Protein kinases Mytl and Weel phosphorylate the effector kinase $\mathrm{Cdc} 2 / \mathrm{Cdk} 1$ which forms a complex with cyclin $\mathrm{B}$. The complex is activated by the removal of phosphate by the protein phosphatase Cdc25 allowing the cells to enter mitosis. (d) Cdt-induced DNA damage resulting in arrest at either the $G_{1}$ or $G_{2}$ checkpoint. DNA damage sensor proteins are recruited to the repair site depending on the cell type either the ataxia telangiectasia mutated/ATM and Rad3-related (ATR/ATM) or p53 pathway is initiated. Arrest at the $\mathrm{G}_{1}$ phase of the cell cycle occurs when the phosphorylated tumor suppressor protein p53 complex mediates the upregulation of p21 which inactivates a Cdc2-cyclin E complex and the proliferating cell nuclear antigen (PCNA). Cdt-induced DNA damage can also trigger a response by the DNA damage sensor proteins 
leading to activation of the ATM and ATR checkpoint pathways. In these pathways the effector kinases Chk1 and Chk2 phosphorylate, and therefore inactivate Cdc25. Activation of the ATM pathway can also lead to the initiation of a survival pathway in which the ATM protein kinase dephosphorylates the neuroepithelioma transforming protein, Net1, which activates RhoA which in turn activates the RhoA activated kinases (ROCK). (e) Putative pathway by which CdtB may affect the phosphatidylinositol-3-kinase (PIK ${ }_{3}$ ) signaling pathway and the production of proinflammatory or anti-inflammatory cytokines. CdtB may function as a phosphatidylinositol-3,4,5-triphosphate 3phosphatase (PTEN) that removes a phosphate group from phosphatidylinositol-3,4,5-triphosphate ( $\left.\mathrm{PIP}_{3}\right)$ present in the plasma membrane. This depletion of $\mathrm{PIP}_{3}$ in lymphocytes inactivates the Akt pathway leading to cell cycle arrest and apoptosis. In macrophages, $\mathrm{PIK}_{3}$ may be activated by toll-like receptors (TLRs) in the cell membrane resulting in the synthesis of $\mathrm{PIP}_{3}$ and the activation of Akt. This activator of anabolic signaling pathways acts on the glycogen synthase kinase-3 (GSK3 $\beta$ ). GSK3 $\beta$ and phosphorylated GSK3 $\beta$ direct the pathway toward the synthesis of proinflammatory and anti-inflammatory cytokines, respectively. The mTOR (mammalian target of rapamycin) protein complex is also regulated by the Akt kinase and participates in the control of protein synthesis and cell growth. Additional details are provided in the text. CBP: CREB-binding protein; CREB: CAMP response element binding protein; TLR: toll-like receptor. The pathways were compiled and modified from those described in other studies [89, 90, 95, 119, 177, 212].

with cyclin B. The inhibition of Cdc2 dephosphorylation blocks progression of the cells to mitosis (Figure 4(d)). Toxins that modulate the eukaryotic cell cycle have been termed cyclomodulins $[89,112]$.

ATM induced Chk2 can also send the cells on an apoptotic pathway due to accumulation of phosphorylated p53 [113]. Guerra et al. [114] found that the transcription factor Myc contributes to the activation of the ATM-dependent induction of apoptosis. The data indicated that Myc stimulates ATM phosphorylation and supports expression of Nbs1 and nuclear translocation. Several groups have published evidence, based on the activation of caspases, mitochondrial damage, decreased cell size, and DNA fragmentation, that the $H d C d t$ and $A a C d t$ induce apoptosis in lymphocytes in addition to the $G_{2}$ arrest $[107,115,116]$.

Activation of the ATM pathway in response to the $H d C d t$ in HeLa and HCT116 cells (colorectal carcinoma) can lead to the initiation of a survival pathway in addition to the Chk2mediated $\mathrm{G}_{2} / \mathrm{M}$ arrest [81]. In this pathway, the ATM protein kinase dephosphorylates the neuroepithelioma transforming protein, Netl, a RhoA-specific guanine nucleotide exchange factor (GEF). This reaction leads to the activation of the GTPase, RhoA, that is associated with extended cell survival [78]. RhoA activated kinases (ROCK) are required for the induction of actin stress fibers [81, 82, 86]. Activation of a survival pathway by the Cdt implies that some chronic bacterial infections could support the malignant transformation of cells [81].

(3) Phosphatidylinositol-3,4,5-triphosphate 3-Phosphatase Activity. The fact that $\mathrm{CdtB}$ is a member of the large metalloenzyme superfamily led to the proposal that the toxin acted upon susceptible cells or cell lines by dephosphorylation of the Weel kinase or Cdc25 phosphatase [117]. These two enzymes are important for regulating the phosphorylation of tyrosine residues in $\mathrm{Cdc} 2$ kinase. An increase in Cdc2 phosphorylation leads to cell cycle arrest. This rationale led to the hypothesis that the primary mode of action of CdtB is that of a phosphatase rather than that of a nuclease. Additional support for the phosphatase mode of action came from studies showing that recombinant $A a C d t B$ behaved as a PTEN in lymphoid cell lines [118]. This enzyme is a hydrolase that removes a phosphate group from phosphatidylinositol3,4,5-triphosphate $\left(\mathrm{PIP}_{3}\right)$ found in the plasma membrane of cells. $\mathrm{PIP}_{3}$ activates downstream signaling components such as the protein kinase Akt, an activator of anabolic signaling pathways necessary for cell growth. It was proposed that the action of the Cdt in lymphocytes causes a depletion of $\mathrm{PIP}_{3}$ which in turn inactivates the Akt pathway leading to cell cycle arrest and apoptosis. This same group expanded their examination of the PTEN activity of the AaCdt to include human macrophages [119]. Unlike lymphocytes, macrophages did not undergo Cdt-mediated apoptosis. The $\mathrm{PIP}_{3}$ signaling pathway has been implicated in the regulation of the cellular proinflammatory response. $\mathrm{PIP}_{3}$ is made from phosphatidylinositol-4,5-diphosphate $\left(\mathrm{PIP}_{2}\right)$ via phosphorylation by the lipid kinase phosphatidylinositol-3-kinase $\left(\mathrm{PIK}_{3}\right)$. In macrophages, $\mathrm{PIK}_{3}$ may be activated by toll-like receptors (TLRs) in the plasma membrane [120]. Inactivation of glycogen synthase kinase-3 (GSK3 $\beta$ ) by phosphorylation regulates the transcription factors, CREB (cAMP response element binding protein) and NF- $\kappa \mathrm{B}$, via the transcription activator CREB-binding protein (CBP), thereby altering cytokine synthesis (Figure 4(e)). The mTOR (mammalian target of rapamycin) protein complex also belongs to the $\mathrm{PIK}_{3}$ pathway [121]. This protein complex is involved in the control of protein synthesis and cell growth and is regulated by the Akt kinase [119, 122].

(4) Cell Signaling Activities. It has been reported that the synthesis of interleukin (IL)- $1 \beta$, IL- 6 , and IL- 8 in human peripheral blood mononuclear cells (PBMC) is stimulated by the $A a C d t ~[38]$ and IL-8 in human embryo intestinal epithelial cells (INT407) is induced by the CjCdt [122]. In addition, nitric oxide production was altered in macrophage cultures by the presence of $A a \mathrm{Cdt}$ and the levels of IL$1 \beta$, IL-10, IL-20, and TNF- $\alpha$ increased [123]. The $A a C d t$ may modulate macrophage function in vivo by changing the proinflammatory/anti-inflammatory cytokine balance. However, recombinant $A a C d$ failed to stimulate IL-1 $\beta$ in human periodontal ligament fibroblasts (HPLF) but upregulated IL6 and the receptor activator of NF- $\kappa$ B ligand (RANKL) [124, 125]. Another report found that human gingival fibroblasts (HGF) challenged with $A$. actinomycetemcomitans exhibited increased expression of IL- 6 and IL- 8 [126]. This increase in expression was not attributed to a specific product, but the Cdt is a reasonable candidate. RANKL was also upregulated in response to the $H d \mathrm{Cdt}$ in a T-lymphocyte leukemia cell line (Jurkat) [127]. RANKL is a member of the TNF ligand superfamily and binds to its associated receptor RANK on 
osteoclast progenitor cells [128]. This action leads to the differentiation of the progenitor cells into bone-resorbing osteoclasts [129]. Since expression of these molecules is involved in the induction of osteoclast differentiation, they have a central role in the regulation of bone resorption which is a key feature of periodontitis $[130,131]$. A recent review by Belibasakis and Bostanci [132] presents a thorough discussion of the role of the Cdt on host inflammatory responses and associated bone remodeling events.

\section{AB Toxin Assembly and Cell Intoxication}

There are common features of the $\mathrm{AB}$ toxins for assembly of the holotoxin complex and intoxication of target cells. Synthesis and assembly of both the A and B chains or subunits are required for these toxins to be effective against susceptible cells. The B chains, in either monomeric or multimeric forms are essential for the delivery of the A chain into the cell. Since these toxins act on internal pathways or processes, unlike pore-forming or membrane-damaging toxins, it is essential that the A chains are transported across the plasma membrane. Endocytosis appears to be a common mechanism for internalization of the A chain. Anthrax toxin can be considered a minor exception to the general mode of $\mathrm{AB}$ toxin assembly since active holotoxins are heterogeneous. Holotoxins can consist of the B chain polymer together with various combinations of the A chains (see Figure 1) [15]. The SeCdt represents another deviation from the standard internalization process because $S$. enterica serovar Typhi carries and expresses only the $c d t B$ gene [46]. It has been hypothesized that delivery of the SeCdt to cells is carried out by internalized bacteria. The bacteria invade cells via a membrane enclosed organelle in macrophages known as a Salmonella-containing vacuole (SCV) $[133,134]$. The bacteria replicate in this vacuole which may intersect with the Golgi apparatus or endoplasmic reticulum (ER) where the secreted $\mathrm{CdtB}$ protein can be released for processing.

Comparison of representative examples of several of the most common classes of $\mathrm{AB}$ toxin demonstrates the similarities and differences among the cell intoxication mechanisms (Figure 5). As stated previously, the ricin holotoxin binds to a glycoprotein or glycolipid receptor, containing a terminal $\beta$-D-galactopyranoside residue, on the surface of susceptible cells [8]. There are two binding sites in the $\mathrm{B}$ chain. The holotoxin enters the cell via endocytic mechanisms enlisting primarily both clathrin-coated pits and clathrin-independent membrane invaginations [135]. Binding of the toxin to the membrane and endocytosis may be concentrated in areas containing lipid rafts since these processes are affected by cholesterol depletion. The results of cholesterol depletion experiments indicated that lipid rafts may also be important for the transfer of ricin from endosomes to the Golgi apparatus. The complex collection of proteins that mediate retrograde transport of proteins from endosomes to the Golgi apparatus has been summarized [136], but their specific roles in ricin transport have not been detailed. Likewise, details of the mechanism of retrograde transport of ricin from the Golgi apparatus to the ER have not been worked out.
However, there is some data to suggest that phospholipase A2 contributes to the process $[137,138]$. Finally, ricin translocation to the cytosol may depend on sequences enriched in hydrophobic amino acids [139].

There are many similarities between the mechanism of cell intoxication by ricin and Shiga toxin. This is expected since both contain an A chain comprised of $\mathrm{N}$-glycosidase. The Shiga toxin-receptor Gb3 resides in the outer leaflet of the plasma membrane [13]. Shiga toxin binding to susceptible cells is affected by the concentration of Gb3 in the membrane, the isoforms present, and the types of other glycosphingolipids adjacent to Gb3 and cholesterol. However, it has not been unequivocally established if lipid rafts are involved [135]. Similar to ricin, multiple endocytic processes, including clathrin-coated pits, bring Shiga toxin into the cell. Unlike ricin, clathrin appears to be required for carrying Shiga toxin from early endosomes to the Golgi apparatus [136]. Two mammalian cell SNARE complexes, containing the proteins GS15, GS28, syntaxin-5, syntaxin-6, and syntaxin-16, YKT6, VTIla, and VAMP4, play roles in the retrograde transport of the toxin. Also like ricin, Shiga toxin translocates from the ER to the cytosol due to hydrophobic membrane-spanning domains in the protein [140].

Anthrax is an $\mathrm{A}_{2} \mathrm{~B}_{7}$ class toxin with each of the LF and EF A chains having distinct modes of action [15]. To initiate the assembly process, a monomer of the PA B chain binds to the ATR (Figure 5). Previously characterized cell surface receptors tumor endothelium marker-8 (TEM8), capillary morphogenesis protein-2 (CMG2), and integrin $\beta 1$ have been implicated in PA binding due to the presence of a von Willebrand factor A (vWA) domain in the proteins [141145]. However, a recent study employing a murine model has shown that TEM 8 may be the only receptor candidate to function in vivo [143]. The toxin-receptor complex is associated with lipid rafts and endocytosis is clathrin dependent [146]. Once PA binds to the ATR, a small amino terminal fragment of the former protein is removed by furin-like proteases. This processing triggers PA to spontaneously form a heptamer, or possibly an octamer. The polymerized PA complex then binds 3-4 LF and/or EF chains $[147,148]$. The holotoxin enters the cell by endocytosis. The holotoxin forms a membrane channel in the early endosome which allows the translocation of the LF and EF subunits to the cytosol.

Botulinum toxin is made as a single inactive polypeptide of approximately $150 \mathrm{kDa}$ that is internalized by receptormediated endocytosis. However, relatively little is known about this process in comparison to the other members of the $\mathrm{AB}$ toxin family. The polypeptide appears to bind to a receptor in the early endosome (Figure 5 ). The toxin recognizes gangliosides and has the greatest affinity for GT1b (Neu5Ac $\alpha(2-3) D-G a l p \beta(1-3) D-G a l N A c \beta(1-4)[N e u 5 A c \alpha(2-$ 8)Neu5Ac $\alpha(2-3)] \mathrm{D}-G a l p \beta(1-4) D-G l c p \beta(1-1)$-ceramide) [149]. The polypeptide is composed of a $100 \mathrm{kDa}$ peptide, representing the $\mathrm{B}$ chain (heavy chain) and a $50 \mathrm{kDa} A$ chain (light chain). The heavy and light chains are nicked by a protease but held together by a single disulfide bond. Dissolution of the disulfide bridge releases the light chain into the cytosol while the heavy chain remains in the endosome [150]. 


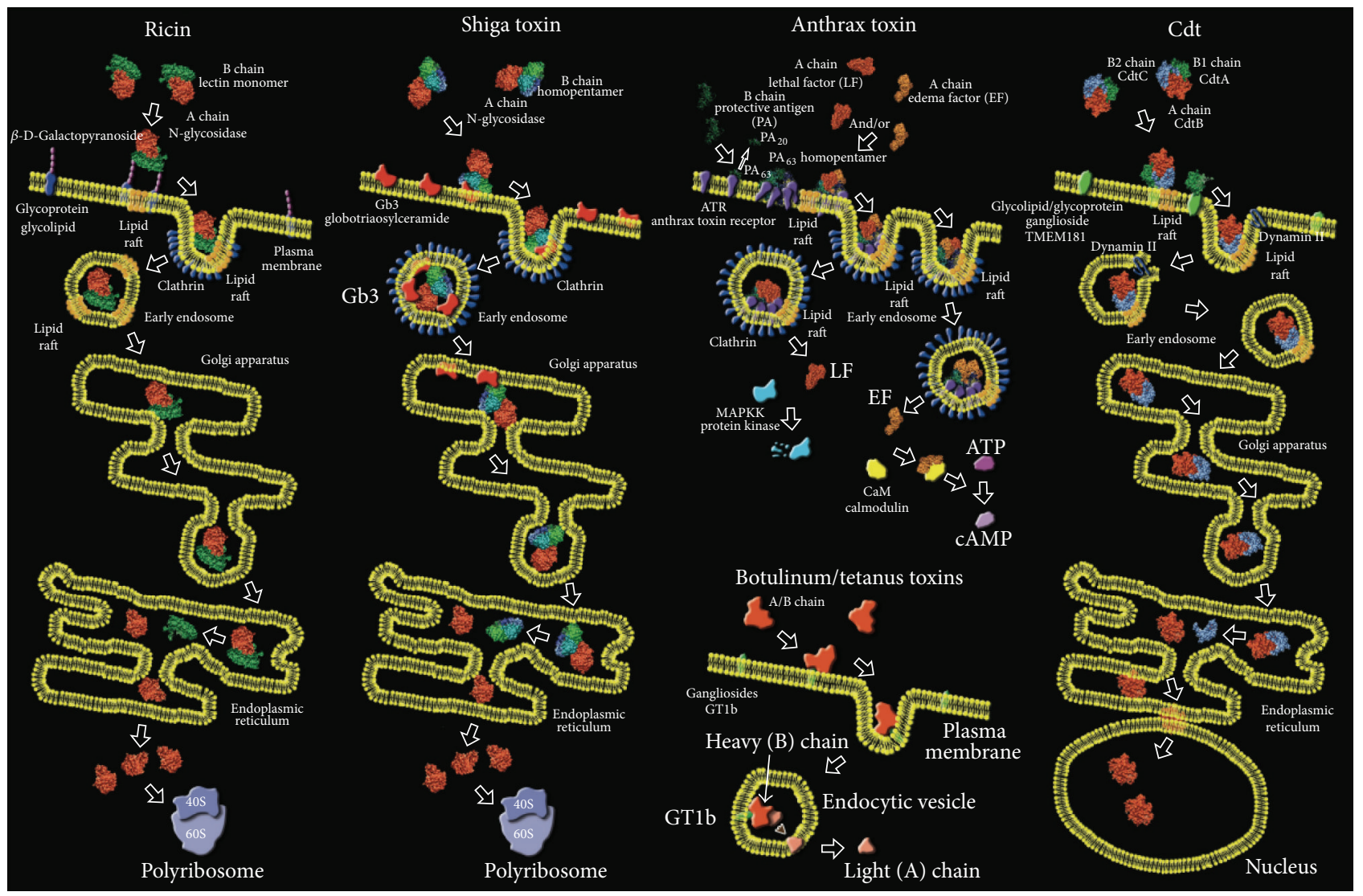

FIgURE 5: Comparison of cell intoxication pathways of representative $\mathrm{AB}$ toxins. Based on the available information, the toxins shown may or may not bind to lipid rafts and enter the cell by either a clathrin-dependent or independent receptor-mediated endocytosis. Anthrax, botulinum, and tetanus toxins are not translocated to the Golgi apparatus and endoplasmic reticulum (ER) but enter the cytosol from early endosomes. Additional details are provided in the text. Unique features of Cdt intoxication are (i) endocytosis of CdtB and CdtC rather than the intact holotoxin, (ii) dynamin II participation in early endosome formation, (iii) translocation of CdtB by a non-ER-associated degradation (ERAD) pathway, and (iv) translocation of CdtB across the nuclear membrane via a nuclear localization signal (NLS).

Studies of the $A a C d t$ have provided insight into the mechanism by which the Cdt holotoxin is synthesized and assembled in the bacterium. Each of the three subunits are translated with an $\mathrm{N}$-terminal signal or leader sequence that allows the proteins to traverse the cytoplasmic membrane of the Gram-negative bacterium. It has been hypothesized that $\mathrm{CdtB}$ and $\mathrm{CdtC}$ protein precursors are transported across the membrane via a sec-dependent pathway coordinated with cleavage of the leader sequences by signal peptidase I [151]. This results in accumulation of the mature proteins in the periplasmic space. Precursor CdtA protein is processed by signal peptidase II and modified with a glycerolipid. The modified hydrophobic CdtA is inserted into the periplasmic space side of the outer membrane, via a lipid-binding consensus sequence (lipobox), where it forms a complex with the mature forms of $\mathrm{CdtB}$ and $\mathrm{CdtC}$. The precursor holotoxin is then processed by an unidentified protease, possibly signal peptidase II, that removes the $\mathrm{N}$-terminus along with the glycerolipid. This cleavage step allows the now hydrophilic holotoxin to exit the bacterium. Indeed, there is support for a role of a truncated CdtA in the assembly of the mature toxin since both 23- and $17-\mathrm{kDa}$ CdtA peptides were found in $H$. ducreyi extracts [152]. Similar results were reported for the AaCdt [153].

As discussed in Section 3.3.1, there are three types of molecules, N-linked fucose containing glycoproteins, gangliosides, and transmembrane proteins, that may serve as receptor candidates for the various Cdts and in various types of susceptible cells $[55,64,72]$. The Cdt appears to recognize at least one of these types of receptors and most likely binds to the cell via the CdtA aromatic patch region and the groove between the CdtA-CdtC heterodimer (see Figure 3). Biochemical and flow cytometry analyses of immunolabeled cells suggested that $\mathrm{CdtA}$ and $\mathrm{CdtC}$ mediate toxin binding to target cell membranes and facilitate internalization of the active CdtB subunit $[48,64,154]$. There is evidence that lipid rafts may also be important for the binding of some Cdts to specific types of cells due to an interaction between the cholesterol concentrated in these membrane domains and the CRAC motif in CdtC [58, 70, 71, 155]. It appears that the $A a C d t$, as well as several other members of the Cdt subfamily, may require the localization of a specific receptor with lipid rafts to maximize binding to the cell surface. 
Experiments performed primarily with the $\mathrm{HdCdt}$ suggest that the toxin enters cells by a dynamin-dependent endocytosis that may be clathrin dependent or independent based on the techniques used to assess this property $[21,86]$. Dynamin, a GTPase, is believed to be a classical regulator that recruits effectors of endocytosis [156, 157]. Several earlier models of Cdt intoxication predicted that the Cdt holotoxin, rather than a CdtB-CdtC dimer or CdtB alone, is taken up by early endosomes [71, 158, 159]. However, using a precise protein tagging technology in combination with live-cell imaging, we found that $\mathrm{CdtA}$, and a smaller amount of $\mathrm{CdtC}$, from the $\mathrm{AaCdt}$, remains on the cell surface during the intoxication of $\mathrm{CHO}$ cells [160]. A significant amount of $\mathrm{CdtC}$ was found, in addition to $\mathrm{CdtB}$, inside the cells. These observations supported data from our earlier adhesion studies that indicated that the CdtA subunit may have a more active role than $\mathrm{CdtC}$ in the binding of the holotoxin to cells $[56,59]$ and that $\mathrm{CdtC}$ could be detected, by immunofluorescence microscopy, inside cells [39]. Based on data from our experiments and those of Guerra et al. $[86,155,159]$, a general model for the Cdt intoxication process is presented (Figure 5). In this model, the Cdt binds to a cell surface receptor via the CdtA and CdtC subunits. This binding may take place in areas of the membrane that contain lipid rafts [70, 71]. However, it should be pointed out that Cdt binding to cells may be either cholesterol-dependent or independent based on the specific cell type or cell line, species-specific origin of the toxin, toxin concentration, and reorganization of the putative receptor for toxin binding within protein components of the cell membrane $[58,161]$. After initial binding, CdtA remains on the surface of the cell in association with the specific receptor. A CdtB-CdtC heterodimer undergoes endocytosis due to an association of $\mathrm{CdtC}$ with the lipid raft. For this model, we proposed that the endocytosis is clathrin independent because it has been reported that knock-down of the clathrin gene by RNA interference does not reduce Cdt activity in intoxicated cells [86]. However, there is conflicting data suggesting that the endocytic uptake of the HdCdt in HeLa and HEp-2 cells depends on clathrin-coated pits [21]. The early endosome is formed with the help of dynamin II and carries the CdtB$\mathrm{CdtC}$ complex to the Golgi apparatus where it is sulfated. $\mathrm{CdtB}$ is then transferred to the ER where it is translocated in a retrograde fashion and glycosylated. CdtB is translocated by a non-ER-associated degradation (ERAD) pathway because the protein does not enter the cytosol but is targeted to the nucleus. We support the possibility that $\mathrm{CdtC}$ is also delivered to the Golgi apparatus and ER in complex with $\mathrm{CdtB}$. However, CdtC most likely undergoes degradation by the usual ERAD pathway.

CdtB enters the nucleus of the cell via the ER. In a fluorescent tagging approach combined with the isolation of nuclei from intoxicated $\mathrm{CHO}$ cells, we found that the $\mathrm{AaCdtB}$ reaches the nucleus within 4.5 hours after intoxication [160]. These results were in good agreement with those of several studies reviewed in Guerra et al. [86]. The CjCdtB was detected in the nucleus of COS-1 and REF52 cells 4 hours after microinjection [75]. CdtB can apparently cross the ER and nuclear membranes due to the presence of a nuclear localization signal (NLS) sequence. Two different NLS sequences have been reported in $A a C d t B$ and EcIICdtB. The $A a C d t B$ NLS is comprised of amino acids 48-124 in the amino-terminal part of the protein [83]. In contrast, EcIICdtB NLS was located in two regions comprised of amino acids 195-210 and 253-268 [162]. A mutagenesis approach was used to show that both types of NLS sequences contributed to nuclear translocation. Changing tandem arginine residues in the latter putative EcIICdtB NLS to threonine and serine had no effect on the in vitro DNA activity of CdtB but reduced $\mathrm{CdtB}$ translocation to the nucleus and induction of cell cycle arrest. We obtained similar results when the consecutive arginine residues were mutated in the $\mathrm{AaCdtB}$ [160]. When we made amino acid substitutions for the two arginine residues located in the putative NLS site described by Nishikubo et al. [83], there was no effect on the activity of the reconstituted toxin or nuclear localization of CdtB. It is possible that monopartite or bipartite arginine and/or lysine residues necessary for classical NLS function may not be required by this atypical NLS.

\section{Cell Tropism of the Cdt}

The ability of the Cdts to exhibit a broad cell tropism is one of the intriguing properties of this subclass of Ab toxins. The species-specific Cdts, as a group, usually cause cell distention, cell cycle arrest in either the $\mathrm{G}_{1} / \mathrm{S}$ or $\mathrm{G}_{2} / \mathrm{M}$ transition phase, and/or apoptosis in a variety of mammalian cell types [88]. The effects appear to be cell-type specific $[89,90]$. In general, rapidly proliferating cells seem to be most sensitive to the Cdt. For example, cells within the deeper layers of epithelium should be good targets for the toxin since they continuously proliferate prior to terminal differentiation as they migrate towards the epithelial surface [163].

5.1. Epithelioid Cells. Human epithelial-like cell lines such as HeLa $[7,91,104,109,164]$ and HEp-2 $[38,165]$ are arrested at the $\mathrm{G}_{2} / \mathrm{M}$ phase transition by a variety of the specifies-specific Cdts. A well-known human colon carcinoma cell line, Caco2 [91], and two human keratinocyte cell lines, HaCat [108, 166] and Henle-407 (intestinal epithelial cells) [75], are also sensitive to the $\mathrm{CjCdt}$ and $\mathrm{HdCdt}$. These epithelioid cell lines typically are arrested at the $\mathrm{G}_{2} / \mathrm{M}$ interphase of the cell cycle when exposed to the AaCdt. Although Caco-2 cells undergo the characteristic cell cycle arrest at the $\mathrm{G}_{2} / \mathrm{M}$ transition, it has been reported that no prior cell distention was evident [91]. It is not known why distention fails to occur in some types of cells when exposed to the toxin. Perhaps effects of the Cdt on the expression of scaffolding and structural proteins varies among different cell types.

We have shown that KB cells, thought to have originated from epidermoid carcinomas of the larynx, are sensitive to the AaCdt [165]. The KB cell line has traditionally been used to study A. actinomycetemcomitans invasion [167-169]. We also found that an immortalized human orolabial cell line (GMSM-K), transformed with simian virus (SV40) [170], is particularly sensitive to the toxin $[61,171]$. This cell line was employed as an early epithelial cell model for the $\mathrm{A} a \mathrm{Cdt}$ prior 
to our ability to culture primary human gingival epithelial cells (HGEC). Interestingly, this cell line was arrested at the $S$ phase of the cell cycle in response to the toxin. Fedor et al. [84] found that a low dose of the EcCdt progressively induces DNA double-strand breaks in cells in the $S$ phase. Cells isolated from the epithelial layers of human gingival tissue, obtained from crown-lengthening procedures performed on clinically healthy adults, were arrested at the $\mathrm{G}_{2} / \mathrm{M}$ interphase of the cell cycle when exposed to recombinant $A a C d t$ [172]. Immortalized human gingival keratinocytes, exposed to a Cdt-containing extract from $A$. actinomycetemcomitans, also exhibited cell cycle arrest at $\mathrm{G}_{2} / \mathrm{M}$ [173]. The ability of the $A a C d t$ to inhibit the proliferation of primary and immortalized HGEC provided supporting evidence that the toxin could have a significant role in damaging the gingival epithelial layer important for protecting the underlying connective tissue and tooth supporting structures from the damaging effects of oral pathogens.

5.2. Mesenchymal Cells. The results of studies examining the ability of the Cdt to inhibit the proliferation of fibroblasts are mixed. In one report, Chinese hamster lung (Don) fibroblasts were reported to be sensitive to the HdCdt and NIH 3T3 fibroblasts were resistant [166]. Stevens et al. [108] reported only a "modest" inhibitory effect on human foreskin fibroblasts using the $H d C d t$. In another study, extracts of $A$. actinomycetemcomitans containing the $\mathrm{Cdt}$ inhibited DNA synthesis in human periodontal ligament and gingival fibroblasts [101]. The cells became distended but remained viable. Aggregatibacter actinomycetemcomitans extracts that did not contain the toxin failed to elicit these effects. In a follow-up study, this same group reported that the periodontal ligament and gingival fibroblasts were arrested at both the $G_{1}$ and $G_{2} / M$ phases of the cell cycle when treated with the Cdt-containing bacterial extract from $A$. actinomycetemcomitans or recombinant $\mathrm{HdCdt}$ [100]. We found that primary oral fibroblast-like cells including human periodontal ligament fibroblasts (HPLF) [61], human gingival fibroblasts (HGF) [172] cementoblasts [171], and osteoblasts (unpublished observations) appear to be relatively resistant to the DNA-damaging and cell cycle arresting effects of the Cdt. Cells cultured from the connective tissue layer of human gingival explants and identified as fibroblasts (HGF) failed to enter cell cycle arrest following exposure to recombinant AaCdt [172]. It is clear that Cdt intoxication of target cells is very complex set of events that can have different effects on various pathways and may be dependent on the source of toxin, target cell type, and possibly the environment of the cell $[90,100]$.

5.3. T-Lymphocytes. Human $\mathrm{CD} 4^{+}$and $\mathrm{CD} 8^{+}$T lymphocytes as well as monocytes undergo cell cycle arrest, without cell distention, in the $G_{2}$ phase when treated with extracts containing the $A a C d t[106,174]$. Lymphocytes treated with recombinant $A a C D T$ underwent apoptosis via activation of the caspase cascade [116]. There was evidence of a role for $\mathrm{Bcl}-2$, an apoptosis regulator, in pathway [175]. Apoptosis induced by the $A a C d t$ in these cells involved the upregulation of Fas and FasL, downregulation of Bcl-2, and activation of caspase-3 and was dependent on the presence of monocytes [174]. Binding of FasL, the Fas ligand, to the CD95, the Fas receptor, on target cells is one of the pathways that leads to the initiation of apoptosis [176]. Two independent pathways, caspase-dependent (early) apoptotic cell death and caspase-independent (late) cell death, may be involved in Cdt-induced death in some types of T-cells such as the human leukemic cell line MOLT-4 [177, 178].

5.4. Macrophages. Macrophages may be potential in vivo targets of the toxin since it was found that apoptosis in nonproliferating U937 cells required the phosphatidylinositol-3,4,5triphosphate phosphatase activity of recombinant $\mathrm{AaCdtB}$ [179]. However, cell cycle arrest and induction of apoptosis in these cells was dependent on the action of the nuclease activity of this subunit on proliferating cells. There is additional evidence that the $A a C d t$ disrupts macrophages by inhibiting phagocytic activity, modulating nitric oxide production, and altering the expression of proinflammatory and anti-inflammatory cytokines $[123,180]$. Human macrophages exposed to the AaCdt did not exhibit Cdt-induced apoptosis but experienced inhibition of the phosphatidylinositol-4,5bisphosphate 3-kinase signaling pathway and an associated increase in glycogen synthase kinase $3 \beta$ affecting production and secretion of the cytokines IL- $1 \beta$, IL- 6 , and tumor necrosis factor (TNF) $\alpha$ [119].

\section{AB Toxins and Infectious Diseases}

The $\mathrm{AB}$ toxins can be associated with either noninfectious disease or infectious disease. The noninfectious disease types are the toxins produced by plants. These toxins can promote disease when the toxin itself or cellular material containing the toxin is inhaled or ingested by the host. $A B$ toxins produced by bacteria are of the infectious disease type. Diseases associated with these toxins become established when the host becomes infected with the microorganism or spores (anthrax, botulinum, and tetanus toxins) produced by the microorganism. In most cases, the bacterial $A B$ toxins are produced by one to several species within a single genus of the bacterium and represent the primary "virulence factor" in the disease. For example, the botulinum toxin is produced by Clostridium botulinum, C. butyricum, C. baratii, and $C$. argentinense and the primary symptoms of botulism are attributed to the activity of the toxin. Cholera toxin is produced by Vibrio cholerae and the primary symptoms of cholera are due to the activity of the toxin. Many of the $A B$ toxins have each been clearly associated with a single specific disease. In contrast to the other $\mathrm{AB}$ toxins the $\mathrm{Cdt}$ is produced by members of eight different genera of Gramnegative bacteria and can be potentially related to six different diseases (see Table 2). Furthermore, it has been difficult to prove that diseases associated with some Cdt-producing bacteria are due primarily to the activities of the toxin.

6.1. Association of the Cdt with Disease. In site of the genetic diversity of the various Cdts, there is a commonality of 
function based on a connection between the Cdt-producing strains of bacteria and diseases that compromise tissue layers comprised of epithelial or epithelial-related cells. Due to the complexity of mucosal related diseases, cause, and effect, relationships between the toxin and clinical symptoms of disease have had to rely on indirect associations. Often the relationship is based solely on the isolation of Cdt-producing strains from a diseased subject as in a case study reporting the isolation of E. coli $055: \mathrm{K} 59: \mathrm{H} 4$ from a child having a history of gastroenteritis and encephalopathy [181]. Similar approaches have been used to show that EPEC belonging to serogroup O127, isolated from children with diarrhea, contain $c d t$ gene sequences detected by PCR [182]. However, not all of the O127 isolates from the diseased subjects produced the Cdt and some Cdt-producing strains were isolated from control subjects. Enterohemorrhagic E. coli (EHEC) can also be etiological agents for diarrhea and hemolytic uraemic syndrome (HUS), a cause of acute renal failure in children. Escherichia coli $\mathrm{O} 57: \mathrm{H7}$, a $\mathrm{Cdt}^{+}$strain, is a predominant serogroup in HUS and the toxin is capable of contributing to the endothelial or vascular injury associated with the disease [183]. However, disease associations are complicated by the fact that other virulence factors such as endotoxin and Shiga toxin are present in the EHEC.

Attempting to establish a major role for the Cdt in the virulence of $C$. jejuni in cases of acute bacterial gastroenteritis has also been challenging. The Cdt appears to be a predominant virulence factor in Campylobacter sp. [184] and, in addition to endotoxin which is a structural component of all Gram-negative bacteria, it is the only other toxin identified in these species. $\mathrm{Cdt}^{-}$mutants of $C$ jejuni failed to cause gastroenteritis in a NF- $\kappa \mathrm{B}$-deficient mouse model [185]. Other studies have provided evidence that the CjCdt may support the ability of the bacterium to invade tissues in a severe combined immunodeficient (SCID) mouse model [186]. A study examining the role of C. jejuni in human gastroenteritis found that disease in patients infected with $\mathrm{Cdt}^{-}$strains was clinically indistinguishable from that in patients harboring $\mathrm{Cdt}^{+}$strains [187]. It was concluded that Cdt production was not essential for the development of the diarrhea associated with Campylobacter-related disease.

Other studies have examined the role of the $H d \mathrm{Cdt}$ in the formation of ulcers, a characteristic of the sexually transmitted disease (STD), chancroid. Using a rabbit model, it was found that $c d t$ gene knock-out mutants of $H$. ducreyi were just as virulent as the wild-type strain [108, 188]. A combination of a $\mathrm{Cdt}^{-}$strain of $H$. ducreyi and recombinant $H d C d t$ produced inflammatory skin lesions that progressed to ulceration in the same rabbit model [189]. Even though a combination of Haemophilus influenzae and $H d C d t$ failed to cause ulcers to form, a contributory role for other $H$. ducreyi virulence factors could not be ruled out. In a skin pustule formation model employing human volunteers, independent challenges with a $c d t$ gene knock-out mutant and wildtype strain resulted in the development of papules at most sites of infection [190]. The results of several trials indicated that the $H d C d t$ was not required for pustule formation in humans.
6.2. Contribution of the AaCdt to Oral Infectious Disease. Clearly, the variety of cell types and infectious diseases associated with the Cdt subfamily of $\mathrm{AB}$ toxins has added layers of complexity in attempts to unequivocally demonstrate a cause and effect relationship between the toxin and disease at the clinical level. Further complications can be attributed to the presence of multiple virulence factors, including endotoxin, in $\mathrm{Cdt}^{+}$strains. Application of standard epidemiological, serological, and genetic approaches including: (i) identification of $\mathrm{Cdt}^{+}$strains or evidence of $c d t$ gene sequences in diseased but not in control subjects, (ii) presence of Cdt or Cdt-neutralizing antibody titers in diseased and healthy subjects, respectively, and (iii) use of $c d t$ gene knock-out mutants in animal and human disease-related models have for the most part failed to provide strong support for an active in vivo role of the various enteric- and STD-associated Cdts. These same problems have plagued investigations of the $A a \mathrm{Cdt}$. Data from some studies have indicated a correlation between the presence of $\mathrm{Cdt}^{+} A$. actinomycetemcomitans strains and periodontal disease while other studies have failed to find a difference between colonization of subjects with disease by $\mathrm{Cdt}^{+}$and $\mathrm{Cdt}^{-}$strains. A representative collection of studies in which $\mathrm{Cdt}^{+}$and $\mathrm{Cdt}^{-}$strains of $A$. actinomycetemcomitans were quantified by either culturing or PCR in localized aggressive periodontitis (LAP) subjects and clinically healthy controls yielded mixed results in relation to a positive correlation between the toxin and disease [19, 191-197]. In one of these studies, a random cohort of 500 Ghanaian adolescents (mean age 13 years) was examined for the presence of A. actinomycetemcomitans and expression of the $A a C d t$ at baseline and in 397 of the subjects two years later [191]. No statistically significant correlation between $\mathrm{Cdt}^{+}$and $\mathrm{Cdt}^{-}$strains and attachment loss indicative of progression to LAP was observed in the follow-up examination.

Similar conflicting results were obtained when systemic and neutralizing $A a C d t$ antibody titers were measured in diseased and healthy patients [198-200]. Based on these studies, a cause and effect relationship has not been confirmed between the AaCdt and the development of some forms of periodontal disease. To the best of my knowledge, there have not been any reports of studies designed to assess the activities of the Cdt in cases of A. actinomycetemcomitans-involved infectious endocarditis. Aggregatibacter actinomycetemcomitans is a member of the HACEK group of bacteria that cause infective endocarditis in children [201].

In spite of the conflicting data from epidemiological studies, complexities of polymicrobial diseases like LAP and chronic periodontitis, and the limitations of animal models to adequately represent human periodontal disease, significant progress has been made towards identifying an in vivo role for the $\mathrm{AaCdt}$. A significant amount of information has been obtained from studies assessing the effects of the various species-specific Cdts on cells in culture an additional set of new questions can be approached using tissue. The effects of the Cdt on sensitive cells in situ are expected to be different, due to the spatial distribution and unique interactions in tissue, than on the same cells grown in vitro in tissue culture. 
In an elegant study, Ohara and coworkers [202] exposed areas of the gingival sulcus in live rats to recombinant wildtype and mutated $\mathrm{AaCdt}$. The infected tissue was observed in vivo and harvested 1-3 days following exposure to the toxin. Tissue samples were decalcified, embedded in paraffin and sectioned parallel to the long axis of the tooth. Sections were stained with hematoxylin and eosin (H\&E) and proliferating cell nuclear antigen (PCNA) antibody. Cells in the junctional epithelium became desquamated and detached by day three of exposure to the wild-type toxin. The biologically inactive mutated $A a C d t$ had no effect on the tissue. The amount of PCNA staining was significantly reduced in the junctional and gingival epithelia. This observation was an indication that proliferation of the epithelial cells in the tissue was inhibited by the Cdt.

My laboratory examined the effect of recombinant $\mathrm{AaCdt}$ on human gingival tissue obtained from healthy adults having no clinical signs of periodontal disease [172]. As in the case of rat gingiva, we observed extensive desquamation and detachment of the keratinized surface layer of the human tissue and obvious disruption of the underlying spinous layer and rete pegs in H\&E stained paraffin sections by 18 hours of exposure to the toxin. On the gross morphological level, the tissue appeared swollen and the spinous layer became substantially thickened. The epithelial cells were enlarged or distended with an apparent loss of cell junctions as indicated by the increased separation of cells in the tissue. The observed changes in the toxin-treated tissue were dose and time dependent. Tissue exposed to an inactive $A a C d t$ mutated in the $\mathrm{CdtB}$ subunit did not exhibit these major morphological changes. Stained sections of untreated gingival tissue from adult subjects with clinical signs of oral inflammation exhibited the same histological appearance as the AaCdt-treated tissue.

We extended the analysis of AaCdt-treated human gingival tissue by assessing effects on cell junctions in situ [203]. Claudin 1, a primary component of tight junction filaments [204], was poorly detected by immunofluorescence microscopy, in untreated tissue sections. E-cadherin, the major membrane protein in adherens junction complexes $[205,206]$ was readily detected as brightly fluorescent areas surrounding the periphery of the epithelial cells in the tissue. Healthy human gingivae have a relatively high level of Ecadherin in the basal cell layer [207]. Exposure of the tissue to the $A a C d t$ resulted in an observable increase in the relative fluorescence of E-cadherin and redistribution in the cytosol. These changes correlated with an increase in E-cadherin mRNA expression in $50 \%$ of the tissue samples tested. There were also indications that the toxin caused detachment of the basal cells from the basement membrane. Gingival tissue exposed to the mutated $A a C d t$ exhibited minimal changes in E-cadherin distribution. Wild-type toxin-treated tissue also showed increases in $\beta$-catenin and F-actin staining and in mRNA expression in $25 \%$ and $63 \%$, respectively, of the samples examined. Both $\beta$-catenin and actin are cytosolic components of the adherens junction apparatus [206]. Factin assemblies having a morphology similar to that of actin stress fibers accumulated in $\mathrm{CHO}$ cells treated with recombinant EcCdt [208].
The morphological changes observed in AaCdt-treated gingival tissue and the cell tropism exhibited by the toxin (see Section 5) support a possible multipronged attack for the activities of the toxin in oral infectious disease. A model has been proposed outlining the putative contributions of the $A a C d t$ to the cascade of events relevant to the development of periodontal disease [209]. In this model, the AaCdt interacts with three different types of cells, gingival epithelial cells, gingival fibroblasts, and infiltrating inflammatory cells ( $\mathrm{T}$ lymphocytes and macrophages) in three successive stages during the development and progression of the disease. These interactions result in inhibition of cell proliferation and alteration of cell signaling pathways. The coordinated effects of these Cdt-cell interactions could lead to the direct and indirect destruction of tissues characteristic of the periodontal disease.

\section{Conclusions}

The Cdt is an intriguing and novel member of the superfamily of $\mathrm{AB}$ toxins and continues to pose significant challenges in studies of the biology of cytotoxins and their role in disease almost 30 years after the discovery of the first member of this subgroup. One Cdt enigma is that, unlike the other AB toxins, it seems to fail to live up to the tremendous potential it has to be a prominent virulence component in bacterial species associated with major diseases. For example, Campylobacter spp. such as C. jejuni cause campylobacteriosis which is one of the most common gastroenteric infections in developed and developing nations [210]. The bacterium is responsible for 400-500 million cases of diarrhea per year. It is estimated that 2 million cases of campylobacteriosis occur in the United States each year making it the most common bacterial cause of foodborne illness [211]. Yet, it has been difficult to show that the CjCdt, the only toxin other than endotoxin produced by Campylobacter sp., is involved in the disease. Associations between the $H d \mathrm{Cdt}$ and chancroid and the $A a \mathrm{Cdt}$ and some forms of periodontal disease offer very similar scenarios. As discussed in Section 3.1, Cdt-producing organisms do not appear to easily shed their $c d t$ genes even though they have a promiscuous evolutionary history and no obvious selective pressure to enforce maintenance by the producing bacterium. So, a very interesting question that remains unanswered is how can the various species-specific Cdts, which are clearly $\mathrm{AB}$ toxins based on their structural and biological characteristics, not play important roles in infectious diseases specific to the Cdt-producing bacterium?

Another Cdt puzzle is the molecular basis for the extensive heterogeneity. The different Cdts exhibit significant deduced amino acid sequence diversity, a broad host cell range exemplified by heterogeneity in cell attachment mechanisms and variability in the end-point of intoxication. Some Cdts appear to bind specifically structured glycan residues on glycoproteins or glycolipids, certain gangliosides, and/or some types of transmembrane G-protein-coupled receptor proteins. Also, intoxication by some Cdts leads to cell cycle arrest at either the $G_{1}$ or $G_{2} / M$ checkpoint or cell death via an apoptotic pathway. Exhaustive phylogenetic analyses and comparisons within each of the three subunits across 
the species-specific Cdts have been performed to attempt to understand this heterogeneity $[48,158]$. Unfortunately, this approach has been yielded few insights. For example, in spite of the marked sequence diversity among the various specifiesspecific CdtB subunits, the largest genetic distance between clades is 0.8 [158]. The genetic distance is even smaller if the bacteriophage and putative Yersinia CdtBs are removed from the analysis. Furthermore, the amino acid residues important for the DNase-like activity (catalytic site, DNA-binding, and cation binding) are highly conserved. Yet, DNA damage caused by the different CdtBs results in $G_{1}, G_{2} / M$ arrest or apoptosis. Similar to $\mathrm{CdtB}$, the largest genetic distance between clades of CdtA and CdtC is 0.9 and 0.6 , respectively. Therefore, CdtA and CdtC are not more diverse than CdtB which is the most highly conserved of the three subunits. All of the CdtAs have a conserved aromatic patch motif and all CdtAs and CdtCs combine to form a groove in the structure predicted to be an important receptor binding site. However, the various holotoxins appear to recognize different receptors on different types of cells.

Therefore, the extensive body of work that exists for the Cdt has to be extended in order to solve the mysteries of what is arguably the most fascinating $A B$ toxin. As pointed out by a number of other groups working in this field, the obvious current challenges are to decipher the details of the Cdt intoxication process, determine whether there are truly multiple specific receptors or a defined interplay between components in highly specialized regions of the cell membrane, and identify cause and effect relationships to confirm Cdt-mediated pathogenicity. Although the results of current studies are leading to a consensus of opinion that environmental factors dictate different outcomes for $\mathrm{Cdt}$ behavior, there may turn out to be more commonality among the species-specific Cdts than expected.

\section{Conflict of Interests}

The author declares that there is no potential conflict of interests with respect to the authorship and/or publication of this paper.

\section{Acknowledgments}

While attempts were made to be as thorough as possible within the constraints of the review format, a sincere apology is made if some studies were inadvertently omitted. The research performed in the laboratory was supported by the National Institutes of Health Grants DE012593 and DE017679 from the National Institute of Dental and Craniofacial Research.

\section{References}

[1] O. Odumosu, D. Nicholas, H. Yano, and W. Langridge, "AB toxins: a paradigm switch from deadly to desirable," Toxins, vol. 2, no. 7, pp. 1612-1645, 2010.

[2] W. M. Johnson and H. Lior, "Response of Chinese hamster ovary cells to a cytolethal distending toxin (CDT) of Escherichia coli and possible misinterpretation as heat-labile (LT) enterotoxin," FEMS Microbiology Letters, vol. 43, no. 1, pp. 19-23, 1987.

[3] C. L. Pickett, D. L. Cottle, E. C. Pesci, and G. Bikah, "Cloning, sequencing, and expression of the Escherichia coli cytolethal distending toxin genes," Infection and Immunity, vol. 62, no. 3, pp. 1046-1051, 1994.

[4] D. A. Scott and J. B. Kaper, "Cloning and sequencing of the genes encoding Escherichia coli cytolethal distending toxin," Infection and Immunity, vol. 62, no. 1, pp. 244-251, 1994.

[5] N. Nørskov-Lauritsen and M. Kilian, "Reclassification of Actinobacillus actinomycetemcomitans, Haemophilus aphrophilus, Haemophilus paraphrophilus and Haemophilus segnis as Aggregatibacter actinomycetemcomitans gen. nov., comb. nov., Aggregatibacter aphrophilus comb. nov. and Aggregatibacter segnis comb. nov., and emended description of Aggregatibacter aphrophilus to include $\mathrm{V}$ factor-dependent and $\mathrm{V}$ factorindependent isolates," International Journal of Systematic and Evolutionary Microbiology, vol. 56, no. 9, pp. 2135-2146, 2006.

[6] N. A. Moran, P. H. Degnan, S. R. Santos, H. E. Dunbar, and H. Ochman, "The players in a mutualistic symbiosis: insects, bacteria, viruses, and virulence genes," Proceedings of the National Academy of Sciences of the United States of America, vol. 102, no. 47, pp. 16919-16926, 2005.

[7] S. Y. Pérès, O. Marchès, F. Daigle et al., "A new cytolethal distending toxin (CDT) from Escherichia coli producing CNF2 blocks HeLa cell division in G2/M phase," Molecular Microbiology, vol. 24, no. 5, pp. 1095-1107, 1997.

[8] J. M. Lord, L. M. Roberts, and J. D. Robertus, "Ricin: structure, mode of action, and some current applications," The FASEB Journal, vol. 8, no. 2, pp. 201-208, 1994.

[9] S. Olsnes and J. V. Kozlov, "Ricin," Toxicon, vol. 39, no. 11, pp. 1723-1728, 2001.

[10] E. Rutenber, M. Ready, and J. D. Robertus, "Structure and evolution of ricin B chain," Nature, vol. 326, no. 6113, pp. 624626, 1987.

[11] E. C. Sweeney, A. G. Tonevitsky, R. A. Palmer et al., "Mistletoe lectin I forms a double trefoil structure," FEBS Letters, vol. 431, no. 3, pp. 367-370, 1998.

[12] P. J. Hart, A. F. Monzingo, A. Donohue-Rolfe, G. T. Keusch, S. B. Calderwood, and J. D. Robertus, "Crystallization of the B chain of Shiga-like toxin I from Escherichia coli," Journal of Molecular Biology, vol. 218, no. 4, pp. 691-694, 1991.

[13] A. A. Lindberg, J. E. Brown, N. Strömberg, M. WestlingRyd, J. E. Schultz, and K. A. Karlsson, "Identification of the carbohydrate receptor for Shiga toxin produced by Shigella dysenteriae type 1," The Journal of Biological Chemistry, vol. 262, no. 4, pp. 1779-1785, 1987.

[14] S. Schüller, "Shiga toxin interaction with human intestinal epithelium," Toxins, vol. 3, no. 6, pp. 626-639, 2011.

[15] P. Ascenzi, P. Visca, G. Ippolito, A. Spallarossa, M. Bolognesi, and C. Montecucco, "Anthrax toxin: a tripartite lethal combination,” FEBS Letters, vol. 531, no. 3, pp. 384-388, 2002.

[16] D. B. Lacy and R. J. Collier, "Structure and function of anthrax toxin," Current Topics in Microbiology and Immunology, vol. 271, pp. 61-85, 2002.

[17] K. L. May, Q. Yan, and N. E. Tumer, "Targeting ricin to the ribosome," Toxicon, vol. 69, pp. 143-151, 2013.

[18] D. Vanden Broeck, C. Horvath, and M. J. S. de Wolf, "Vibrio cholerae: cholera toxin," International Journal of Biochemistry \& Cell Biology, vol. 39, no. 10, pp. 1771-1775, 2007. 
[19] A. Wheeler and H. S. Smith, "Botulinum toxins: mechanisms of action, antinociception and clinical applications," Toxicology, vol. 306, pp. 124-146, 2013.

[20] B. Bizzini, “Tetanus toxin," Microbiological Reviews, vol. 43, no. 2, pp. 224-240, 1979.

[21] X. Cortes-Bratti, E. Chaves-Olarte, T. Lagergård, and M. Thelestam, "Cellular internalization of cytolethal distending toxin from Haemophilus ducreyi," Infection and Immunity, vol. 68, no. 12, pp. 6903-6911, 2000.

[22] I. Tóth, F. Hérault, L. Beutin, and E. Oswald, "Production of cytolethal distending toxins by pathogenic Escherichia coli strains isolated from human and animal sources: establishment of the existence of a new cdt variant (type IV)," Journal of Clinical Microbiology, vol. 41, no. 9, pp. 4285-4291, 2003.

[23] I. Tóth, J.-P. Nougayrède, U. Dobrindt et al., "Cytolethal distending toxin type I and type IV genes are framed with lambdoid prophage genes in extraintestinal pathogenic Escherichia coli," Infection and Immunity, vol. 77, no. 1, pp. 492-500, 2009.

[24] A. Allue-Guardia, L. Imamovic, and M. Muniesa, "Evolution of a self-inducible cytolethal distending toxin type V-encoding bacteriophage from Escherichia coli O157:H7 to Shigella sonnei," Journal of Virology, vol. 87, no. 24, pp. 13665-13675, 2013.

[25] M. Asakura, A. Hinenoya, M. S. Alam et al., "An inducible lambdoid prophage encoding cytolethal distending toxin (CdtI) and a type III effector protein in enteropathogenic Escherichia coli," Proceedings of the National Academy of Sciences of the United States of America, vol. 104, no. 36, pp. 14483-14488, 2007.

[26] A. Shima, A. Hinenoya, M. Asakura et al., "Molecular characterizations of cytolethal distending toxin produced by Providencia alcalifaciens strains isolated from patients with diarrhea," Infection and Immunity, vol. 80, no. 4, pp. 1323-1332, 2012.

[27] S. Doungudomdacha, A. Volgina, and J. M. DiRienzo, "Evidence that the cytolethal distending toxin locus was once part of a genomic island in the periodontal pathogen Aggregatibacter (Actinobacillus) actinomycetemcomitans strain Y4," Journal of Medical Microbiology, vol. 56, no. 11, pp. 1519-1527, 2007.

[28] W. Kittichotirat, R. E. Bumgarner, S. Asikainen, and C. Chen, "Identification of the pangenome and its components in 14 distinct aggregatibacter actinomycetemcomitans strains by comparative genomic analysis," PLoS ONE, vol. 6, no. 7, Article ID e22420, 2011.

[29] M. P. A. Mayer, L. C. Bueno, E. J. Hansen, and J. M. Dirienzo, "Identification of a cytolethal distending toxin gene locus and features of a virulence-associated region in Actinobacillus actinomycetemcomitans," Infection and Immunity, vol. 67, no. 3, pp. 1227-1237, 1999.

[30] L. D. Cope, S. Lumbley, J. L. Latimer et al., "A diffusible cytotoxin of Haemophilus ducreyi," Proceedings of the National Academy of Sciences of the United States of America, vol. 94, no. 8, pp. 40564061, 1997.

[31] S. C. Kachlany, P. J. Planet, M. K. Bhattacharjee et al., "Nonspecific adherence by Actinobacillus actinomycetemcomitans requires genes widespread in Bacteria and Archaea," Journal of Bacteriology, vol. 182, no. 21, pp. 6169-6176, 2000.

[32] A. Mira, H. Ochman, and N. A. Moran, "Deletional bias and the evolution of bacterial genomes," Trends in Genetics, vol. 17, no. 10, pp. 589-596, 2001.

[33] A. I. Nilsson, S. Koskiniemi, S. Eriksson, E. Kugelberg, J. C. D. Hinton, and D. I. Andersson, "Bacterial genome size reduction by experimental evolution," Proceedings of the National Academy of Sciences of the United States of America, vol. 102, no. 34, pp. 12112-12116, 2005.
[34] H. Ochman, "Lateral and oblique gene transfer," Current Opinion in Genetics and Development, vol. 11, no. 6, pp. 616-619, 2001.

[35] E. P. C. Rocha, "Order and disorder in bacterial genomes," Current Opinion in Microbiology, vol. 7, no. 5, pp. 519-527, 2004.

[36] J. G. Lawrence, "Horizontal and vertical gene transfer: the life history of pathogens," Contributions to Microbiology, vol. 12, pp. 255-271, 2005.

[37] J. G. Lawrence and H. Hendrickson, "Genome evolution in bacteria: order beneath chaos," Current Opinion in Microbiology, vol. 8, no. 5, pp. 572-578, 2005.

[38] S. Akifusa, S. Poole, J. Lewthwaite, B. Henderson, and S. P. Nair, "Recombinant Actinobacillus actinomycetemcomitans cytolethal distending toxin proteins are required to interact to inhibit human cell cycle progression and to stimulate human leukocyte cytokine synthesis," Infection and Immunity, vol. 69, no. 9, pp. 5925-5930, 2001.

[39] X. Mao and J. M. DiRienzo, "Functional studies of the recombinant subunits of a cytolethal distending holotoxin," Cellular Microbiology, vol. 4, no. 4, pp. 245-255, 2002.

[40] K. Saiki, K. Konishi, T. Gomi, T. Nishihara, and M. Yoshikawa, "Reconstitution and purification of cytolethal distending toxin of Actinobacillus actinomycetemcomitans," Microbiology and Immunology, vol. 45, no. 6, pp. 497-506, 2001.

[41] B. J. Shenker, R. H. Hoffmaster, T. L. McKay, and D. R. Demuth, "Expression of the cytolethal distending toxin (Cdt) operon in Actinobacillus actinomycetemcomitans: evidence that the cdtb protein is responsible for G2 arrest of the cell cycle in human T cells," Journal of Immunology, vol. 165, no. 5, pp. 2612-2618, 2000.

[42] S. T. Kai, G. Ong, and P. S. Keang, "Introns in the cytolethal distending toxin gene of Actinobacillus actinomycetemcomitans," Journal of Bacteriology, vol. 187, no. 2, pp. 567-575, 2005.

[43] P. L. Longo, A. C. R. Nunes, J. E. Umeda, and M. P. A. Mayer, "Gene expression and phenotypic traits of Aggregatibacter actinomycetemcomitans in response to environmental changes," Journal of Periodontal Research, vol. 48, no. 6, pp. 766-772, 2013.

[44] E. M. Haase, T. Bonstein, R. J. Palmer Jr., and F. A. Scannapieco, "Environmental influences on Actinobacillus actinomycetemcomitans biofilm formation," Archives of Oral Biology, vol. 51, no. 4, pp. 299-314, 2006.

[45] J. H. Park, J. K. Lee, H. S. Um, B. S. Chang, and S. Y. Lee, "A periodontitis-associated multispecies model of an oral biofilm," Journal of Periodontal Implant Science, vol. 44, no. 2, pp. 79-84, 2014.

[46] E. Haghjoo and J. E. Galán, "Salmonella typhi encodes a functional cytolethal distending toxin that is delivered into host cells by a bacterial-internalization pathway," Proceedings of the National Academy of Sciences of the United States of America, vol. 101, no. 13, pp. 4614-4619, 2004.

[47] C.-C. Chien, N. S. Taylor, Z. Ge, D. B. Schauer, V. B. Young, and J. G. Fox, "Identification of $c d t B$ homologues and cytolethal distending toxin activity in enterohepatic Helicobacter spp," Journal of Medical Microbiology, vol. 49, no. 6, pp. 525-534, 2000.

[48] X. Hu, D. Nesic, and C. E. Stebbins, "Comparative structurefunction analysis of cytolethal distending toxins," Proteins, vol. 62, no. 2, pp. 421-434, 2006.

[49] I. Kursula and R. K. Wierenga, "Crystal structure of triosephosphate isomerase complexed with 2-phosphoglycolate at $0.83-\AA$ resolution," The Journal of Biological Chemistry, vol. 278, no. 11, pp. 9544-9551, 2003. 
[50] L. M. F. Merlo, M. Lunzer, and A. M. Dean, "An empirical test of the concomitantly variable codon hypothesis," Proceedings of the National Academy of Sciences of the United States of America, vol. 104, no. 26, pp. 10938-10943, 2007.

[51] L. Cao, A. Volgina, J. Korostoff, and J. M. DiRienzo, "Role of intrachain disulfides in the activities of the CdtA and CdtC subunits of the cytolethal distending toxin of Actinobacillus actinomycetemcomitans," Infection and Immunity, vol. 74, no. 9, pp. 4990-5002, 2006.

[52] D. Nešić, Y. Hsu, and C. E. Stebbins, "Assembly and function of a bacterial genotoxin," Nature, vol. 429, no. 6990, pp. 429-433, 2004.

[53] T. Yamada, J. Komoto, K. Saiki, K. Konishi, and F. Takusagawa, "Variation of loop sequence alters stability of cytolethal distending toxin (CDT): crystal structure of CDT from Actinobacillus actinomycetemcomitans," Protein Science, vol. 15, no. 2, pp. 362372, 2006

[54] M. Lara-Tejero and J. E. Galán, "CdtA, CdtB, and CdtC form a tripartite complex that is required for cytolethal distending toxin activity," Infection and Immunity, vol. 69, no. 7, pp. 43584365, 2001.

[55] L. A. McSweeney and L. A. Dreyfus, "Carbohydrate-binding specificity of the Escherichia coli cytolethal distending toxin CdtA-II and CdtC-II subunits," Infection and Immunity, vol. 73, no. 4, pp. 2051-2060, 2005.

[56] L. Cao, A. Volgina, C.-M. Huang, J. Korostoff, and J. M. DiRienzo, "Characterization of point mutations in the $c d t A$ gene of the cytolethal distending toxin of Actinobacillus actinomycetemcomitans," Molecular Microbiology, vol. 58, no. 5, pp. 1303-1321, 2005.

[57] P. Stanley, "Glycosylation mutants of animal cells.," Annual Review of Genetics, vol. 18, pp. 525-552, 1984.

[58] A. Eshraghi, F. J. Maldonado-Arocho, A. Gargi et al., "Cytolethal distending toxin family members are differentially affected by alterations in host glycans and membrane cholesterol," The Journal of Biological Chemistry, vol. 285, no. 24, pp. 18199-18207, 2010.

[59] L. Cao, G. Bandelac, A. Volgina, J. Korostoff, and J. M. Dirienzo, "Role of aromatic amino acids in receptor binding activity and subunit assembly of the cytolethal distending toxin of Aggregatibacter actinomycetemcomitans," Infection and Immunity, vol. 76, no. 7, pp. 2812-2821, 2008.

[60] L. Li, C. Ding, J.-L. Duan et al., "A New Functional Site W115 in CdtA Is Critical for Aggregatibacter actinomycetemcomitans Cytolethal Distending Toxin," PLoS ONE, vol. 8, no. 6, Article ID e65729, 2013.

[61] F. Kanno, J. Korostoff, A. Volgina, and J. M. DiRienzo, "Resistance of human periodontal ligament fibroblasts to the cytolethal distending toxin of Actinobacillus actinomycetemcomitans," Journal of Periodontology, vol. 76, no. 7, pp. 1189-1201, 2005.

[62] R. B. Lee, D. C. Hassane, D. L. Cottle, and C. L. Pickett, "Interactions of Campylobacter jejuni cytolethal distending toxin subunits CdtA and CdtC with HeLa cells," Infection and Immunity, vol. 71, no. 9, pp. 4883-4890, 2003.

[63] S. Akifusa, W. Heywood, S. P. Nair, G. Stenbeck, and B. Henderson, "Mechanism of internalization of the cytolethal distending toxin of Actinobacillus actinomycetemcomitans," Microbiology, vol. 151, no. 5, pp. 1395-1402, 2005.

[64] K. Mise, S. Akifusa, S. Watarai, T. Ansai, T. Nishihara, and T. Takehara, "Involvement of ganglioside GM3 in G2/M cell cycle arrest of human monocytic cells induced by Actinobacillus actinomycetemcomitans cytolethal distending toxin," Infection and Immunity, vol. 73, no. 8, pp. 4846-4852, 2005.

[65] A. G. Tonevitsky, O. S. Zhukova, N. V. Mirimanova, V. G. Omelyanenko, N. V. Timofeeva, and L. D. Bergelson, "Effect of gangliosides on binding, internalization and cytotoxic activity of ricin," FEBS Letters, vol. 264, no. 2, pp. 249-252, 1990.

[66] J. Holmgren, P. Fredman, M. Lindblad, A. M. Svennerholm, and L. Svennerholm, "Rabbit intestinal glycoprotein receptor for Escherichia coli heat-labile enterotoxin lacking affinity for cholera toxin," Infection and Immunity, vol. 38, no. 2, pp. 424433, 1982.

[67] D. R. Critchley, C. H. Streuli, S. Kellie, S. Ansell, and B. Patel, "Characterization of the cholera toxin receptor on Balb/c 3T3 cells as a ganglioside similar to, or identical with, ganglioside GM1. No evidence for galactoproteins with receptor activity," Biochemical Journal, vol. 204, no. 1, pp. 209-219, 1982.

[68] K. Sandvig, B. Spilsberg, S. U. Lauvrak, M. L. Torgersen, T.-G. Iversen, and B. van Deurs, "Pathways followed by protein toxins into cells," International Journal of Medical Microbiology, vol. 293, no. 7-8, pp. 483-490, 2004.

[69] N. V. Prokazova, N. N. Samovilova, E. V. Gracheva, and N. K. Golovanova, "Ganglioside GM3 and its biological functions," Biochemistry (Moscow), vol. 74, no. 3, pp. 235-249, 2009.

[70] K. Boesze-Battaglia, D. Besack, T. McKay et al., "Cholesterolrich membrane microdomains mediate cell cycle arrest induced by Actinobacillus actinomycetemcomitans cytolethal-distending toxin," Cellular Microbiology, vol. 8, no. 5, pp. 823-836, 2006.

[71] K. Boesze-Battaglia, A. Brown, L. Walker et al., "Cytolethal distending toxin-induced cell cycle arrest of lymphocytes is dependent upon recognition and binding to cholesterol," The Journal of Biological Chemistry, vol. 284, no. 16, pp. 1065010658, 2009.

[72] J. E. Carette, C. P. Guimaraes, M. Varadarajan et al., "Haploid genetic screens in human cells identify host factors used by pathogens," Science, vol. 326, no. 5957, pp. 1231-1235, 2009.

[73] S. F. Altschul, T. L. Madden, A. A. Schäffer et al., "Gapped BLAST and PSI-BLAST: a new generation of protein database search programs," Nucleic Acids Research, vol. 25, no. 17, pp. 3389-3402, 1997.

[74] C. A. Elwell and L. A. Dreyfus, "DNase I homologous residues in $\mathrm{CdtB}$ are critical for cytolethal distending toxin-mediated cell cycle arrest," Molecular Microbiology, vol. 37, no. 4, pp. 952-963, 2000.

[75] M. Lara-Tejero and J. E. Galan, "A bacterial toxin that controls cell cycle progression as a deoxyribonuclease I-like protein," Science, vol. 290, no. 5490, pp. 354-357, 2000.

[76] K. Hofmann, S. Tomiuk, G. Wolff, and W. Stoffel, "Cloning and characterization of the mammalian brain-specific, $\mathrm{Mg}^{2+}$ dependent neutral sphingomyelinase," Proceedings of the National Academy of Sciences of the United States of America, vol. 97, no. 11, pp. 5895-5900, 2000.

[77] X. Cortes-Bratti, T. Frisan, and M. Thelestam, "The cytolethal distending toxins induce DNA damage and cell cycle arrest," Toxicon, vol. 39, no. 11, pp. 1729-1736, 2001.

[78] T. Frisan, X. Cortes-Bratti, E. Chaves-Olarte, B. Stenerlöw, and M. Thelestam, "The Haemophilus ducreyi cytolethal distending toxin induces DNA double-strand breaks and promotes ATMdependent activation of RhoA," Cellular Microbiology, vol. 5, no. 10, pp. 695-707, 2003.

[79] R. P. Dassanayake, M. A. Griep, and G. E. Duhamel, "The cytolethal distending toxin B sub-unit of Helicobacter hepaticus 
is a $\mathrm{Ca}^{2+}$ - and $\mathrm{Mg}^{2+}$-dependent neutral nuclease," FEMS Microbiology Letters, vol. 251, no. 2, pp. 219-225, 2005.

[80] J. M. DiRienzo, L. Cao, A. Volgina, G. Bandelac, and J. Korostoff, "Functional and structural characterization of chimeras of a bacterial genotoxin and human type I DNAse," FEMS Microbiology Letters, vol. 291, no. 2, pp. 222-231, 2009.

[81] L. Guerra, H. S. Carr, A. Richter-Dahlfors et al., "A bacterial cytotoxin identifies the RhoA exchange factor Netl as a key effector in the response to DNA damage," PLoS ONE, vol. 3, no. 5, Article ID e2254, 2008.

[82] L. Guerra, R. Guidi, I. Slot et al., "Bacterial genotoxin triggers FEN1-dependent RhoA activation, cytoskeleton remodeling and cell survival," Journal of Cell Science, vol. 124, no. 16, pp. 2735-2742, 2011.

[83] S. Nishikubo, M. Ohara, Y. Ueno et al., "An N-terminal Segment of the Active Component of the Bacterial Genotoxin Cytolethal Distending Toxin B (CDTB) Directs CDTB into the Nucleus," Journal of Biological Chemistry, vol. 278, no. 50, pp. 5067150681, 2003.

[84] Y. Fedor, J. Vignard, M.-L. Nicolau-Travers et al., "From singlestrand breaks to double-strand breaks during S-phase: a new mode of action of the Escherichia coli cytolethal distending toxin," Cellular Microbiology, vol. 15, no. 1, pp. 1-15, 2013.

[85] M. Brigotti, P. Accorsi, D. Carnicelli et al., "Shiga toxin 1: damage to DNA in vitro," Toxicon, vol. 39, no. 2-3, pp. 341-348, 2000.

[86] L. Guerra, X. Cortes-Bratti, R. Guidi, and T. Frisan, “The biology of the cytolethal distending toxins," Toxins, vol. 3, no. 3, pp. 172190, 2011.

[87] W. Heywood, B. Henderson, and S. P. Nair, "Cytolethal distending toxin: creating a gap in the cell cycle," Journal of Medical Microbiology, vol. 54, no. 3, pp. 207-216, 2005.

[88] R. N. Jinadasa, S. E. Bloom, R. S. Weiss, and G. E. Duhamel, "Cytolethal distending toxin: a conserved bacterial genotoxin that blocks cell cycle progression, leading to apoptosis of a broad range of mammalian cell lineages," Microbiology, vol. 157, no. 7, pp. 1851-1875, 2011.

[89] E. Oswald, J.-P. Nougayrède, F. Taieb, and M. Sugai, "Bacterial toxins that modulate host cell-cycle progression," Current Opinion in Microbiology, vol. 8, no. 1, pp. 83-91, 2005.

[90] J. L. Smith and D. O. Bayles, "The contribution of cytolethal distending toxin to bacterial pathogenesis," Critical Reviews in Microbiology, vol. 32, no. 4, pp. 227-248, 2006.

[91] C. A. Whitehouse, P. B. Balbo, E. C. Pesci, D. L. Cottle, P. M. Mirabito, and C. L. Pickett, "Campylobacter jejuni cytolethal distending toxin causes a G2-phase cell cycle block," Infection and Immunity, vol. 66, no. 5, pp. 1934-1940, 1998.

[92] M. Lisby and R. Rothstein, "Localization of checkpoint and repair proteins in eukaryotes," Biochimie, vol. 87, no. 7, pp. 579589, 2005.

[93] J. Melo and D. Toczyski, "A unified view of the DNA-damage checkpoint," Current Opinion in Cell Biology, vol. 14, no. 2, pp. 237-245, 2002.

[94] X. Cortes-Bratti, C. Karlsson, T. Lagergård, M. Thelestam, and T. Frisan, "The Haemophilus ducreyi cytolethal distending toxin induces cell cycle arrest and apoptosis via the DNA damage checkpoint pathways," The Journal of Biological Chemistry, vol. 276, no. 7, pp. 5296-5302, 2001.

[95] T. Frisan, X. Cortes-Bratti, and M. Thelestam, "Cytolethal distending toxins and activation of DNA damage-dependent checkpoint responses," International Journal of Medical Microbiology, vol. 291, no. 6-7, pp. 495-499, 2001.
[96] D. C. Hassane, R. B. Lee, and C. L. Pickett, "Campylobacter jejuni cytolethal distending toxin promotes DNA repair responses in normal human cells," Infection and Immunity, vol. 71, no. 1, pp. 541-545, 2003.

[97] K. Harada and G. R. Ogden, "An overview of the cell cycle arrest protein, p21WAF1," Oral Oncology, vol. 36, no. 1, pp. 3-7, 2000.

[98] T. Sato, T. Koseki, K. Yamato et al., "p53-independent expression of p21CIP1/WAF1 in plasmacytic cells during G2 cell cycle arrest induced by Actinobacillus actinomycetemcomitans cytolethal distending toxin," Infection and Immunity, vol. 70, no. 2, pp. 528-534, 2002.

[99] W. R. Taylor and G. R. Stark, "Regulation of the G2/M transition by p53," Oncogene, vol. 20, no. 15, pp. 1803-1815, 2001.

[100] G. N. Belibasakis, A. Mattsson, Y. Wang, C. Chen, and A. Johansson, "Cell cycle arrest of human gingival fibroblasts and periodontal ligament cells by Actinobacillus actinomycetemcomitans: involvement of the cytolethal distending toxin," APMIS, vol. 112, no. 10, pp. 674-685, 2004.

[101] G. Belibasakis, A. Johansson, Y. Wang et al., "Inhibited proliferation of human periodontal ligament cells and gingival fibroblasts by Actinobacillus actinomycetemcomitans: involvement of the cytolethal distending toxin," European Journal of Oral Science, vol. 110, no. 5, pp. 366-373, 2002.

[102] C. Comayras, C. Tasca, S. Y. Pérès, B. Ducommun, E. Oswald, and J. de Rycke, "Escherichia coli cytolethal distending toxin blocks the HeLa cell cycle at the G2/M transition by preventing cdc2 protein kinase dephosphorylation and activation," Infection and Immunity, vol. 65, no. 12, pp. 5088-5095, 1997.

[103] J. de Rycke, V. Sert, C. Comayras, and C. Tasca, "Sequence of lethal events in HeLa cells exposed to the G2 blocking cytolethal distending toxin," European Journal of Cell Biology, vol. 79, no. 3, pp. 192-201, 2000.

[104] N. Escalas, N. Davezac, J. De Rycke, V. Baldin, R. Mazars, and B. Ducommun, "Study of the cytolethal distending toxininduced cell cycle arrest in HeLa cells: involvement of the CDC25 phosphatase," Experimental Cell Research, vol. 257, no. 1, pp. 206-212, 2000.

[105] V. Sert, C. Cans, C. Tasca et al., "The bacterial cytolethal distending toxin (CDT) triggers a G2 cell cycle checkpoint in mammalian cells without preliminary induction of DNA strand breaks," Oncogene, vol. 18, no. 46, pp. 6296-6304, 1999.

[106] B. J. Shenker, T. McKay, S. Datar, M. Miller, R. Chowhan, and D. Demuth, "Actinobacillus actinomycetemcomitans immunosuppressive protein is a member of the family of cytolethal distending toxins capable of causing a G2 arrest in human T cells," Journal of Immunology, vol. 162, no. 8, pp. 4773-4780, 1999.

[107] B. J. Shenker, D. R. Demuth, and A. Zekavat, "Exposure of lymphocytes to high doses of Actinobacillus actinomycetemcomitans cytolethal distending toxin induces rapid onset of apoptosismediated DNA fragmentation," Infection and Immunity, vol. 74, no. 4, pp. 2080-2092, 2006.

[108] M. K. Stevens, J. L. Latimer, S. R. Lumbley et al., "Characterization of a Haemophilus ducreyi mutant deficient in expression of cytolethal distending toxin," Infection and Immunity, vol. 67, no. 8, pp. 3900-3908, 1999.

[109] M. Sugai, T. Kawamoto, S. Y. Pérès et al., "The cell cycle-specific growth-inhibitory factor produced by Actinobacillus actinomycetemcomitans is a cytolethal distending toxin," Infection and Immunity, vol. 66, no. 10, pp. 5008-5019, 1998.

[110] N. S. Taylor, Z. Ge, Z. Shen, F. E. Dewhirst, and J. G. Fox, "Cytolethal distending toxin: a potential virulence factor for 
Helicobacter cinaedi," Journal of Infectious Diseases, vol. 188, no. 12, pp. 1892-1897, 2003.

[111] J. Smith, L. M. Tho, N. Xu, and D. A. Gillespie, "The ATM-Chk2 and ATR-Chk1 pathways in DNA damage signaling and cancer," Advances in Cancer Research, vol. 108, pp. 73-112, 2010.

[112] J.-P. Nougayrède, F. Taieb, J. de Rycke, and E. Oswald, "Cyclomodulins: bacterial effectors that modulate the eukaryotic cell cycle," Trends in Microbiology, vol. 13, no. 3, pp. 103-110, 2005.

[113] Y. Shiloh, "ATM and related protein kinases: safeguarding genome integrity," Nature Reviews Cancer, vol. 3, no. 3, pp. 155$168,2003$.

[114] L. Guerra, A. Albihn, S. Tronnersjö et al., "Myc is required for activation of the ATM-dependent checkpoints in response to DNA damage," PLoS ONE, vol. 5, no. 1, Article ID e8924, 2010.

[115] V. Gelfanova, E. J. Hansen, and S. M. Spinola, "Cytolethal distending toxin of Haemophilus ducreyi induces apoptotic death of Jurkat T cells," Infection and Immunity, vol. 67, no. 12, pp. 6394-6402, 1999.

[116] B. J. Shenker, R. H. Hoffmaster, A. Zekavat, N. Yamaguchi, E. T. Lally, and D. R. Demuth, "Induction of apoptosis in human T cells by Actinobacillus actinomycetemcomitans cytolethal distending toxin is a consequence of G2 arrest of the cell cycle," Journal of Immunology, vol. 167, no. 1, pp. 435-441, 2001.

[117] M. Dlakic, "Is CdtB a nuclease or a phosphatase?" Science, vol. 291, article 547, no. 5504, 2001.

[118] B. J. Shenker, M. Dlakić, L. P. Walker et al., "A novel mode of action for a microbial-derived immunotoxin: the cytolethal distending toxin subunit B exhibits phosphatidylinositol 3,4,5triphosphate phosphatase activity," The Journal of Immunology, vol. 178, no. 8, pp. 5099-5108, 2007.

[119] B. J. Shenker, L. P. Walker, A. Zekavat, M. Dlakic, and K. BoeszeBattaglia, "Blockade of the PI-3K signalling pathway by the Aggregatibacter actinomycetemcomitans cytolethal distending toxin induces macrophages to synthesize and secrete proinflammatory cytokines," Cellular Microbiology, vol. 16, no. 9, pp. 1391-1404, 2014.

[120] K. Hazeki, K. Nigorikawa, and O. Hazeki, "Role of phosphoinositide 3-kinase in innate immunity," Biological \& Pharmaceutical Bulletin, vol. 30, no. 9, pp. 1617-1623, 2007.

[121] L. Asnaghi, P. Bruno, M. Priulla, and A. Nicolin, "mTOR: a protein kinase switching between life and death," Pharmacological Research, vol. 50, no. 6, pp. 545-549, 2004.

[122] T. E. Hickey, A. L. McVeigh, D. A. Scott et al., "Campylobacter jejuni cytolethal distending toxin mediates release of interleukin-8 from intestinal epithelial cells," Infection and Immunity, vol. 68, no. 12, pp. 6535-6541, 2000.

[123] E. S. Ando-Suguimoto, M. P. da Silva, D. Kawamoto, C. Chen, J. M. DiRienzo, and M. P. Mayer, "The cytolethal distending toxin of Aggregatibacter actinomycetemcomitans inhibits macrophage phagocytosis and subverts cytokine production," Cytokine, vol. 66, no. 1, pp. 46-53, 2014.

[124] G. N. Belibasakis, A. Johansson, Y. Wang et al., "Cytokine responses of human gingival fibroblasts to Actinobacillus actinomycetemcomitans cytolethal distending toxin," Cytokine, vol. 30, no. 2, pp. 56-63, 2005.

[125] G. N. Belibasakis, A. Johansson, Y. Wang, C. Chen, S. Kalfas, and U. H. Lerner, "The cytolethal distending toxin induces receptor activator of NF-kappaB ligand expression in human gingival fibroblasts and periodontal ligament cells," Infection and Immunity, vol. 73, no. 1, pp. 342-351, 2005.
[126] Y. Uchida, H. Shiba, H. Komatsuzawa et al., "Expression of IL$1 \beta$ and IL- 8 by human gingival epithelial cells in response to Actinobacillus actinomycetemcomitans," Cytokine, vol. 14, no. 3, pp. 152-161, 2001.

[127] G. N. Belibasakis, M. Brage, T. Lagergård, and A. Johansson, "Cytolethal distending toxin upregulates RANKL expression in Jurkat T-cells," APMIS, vol. 116, no. 6, pp. 499-506, 2008.

[128] H. Hsu, D. L. Lacey, C. R. Dunstan et al., "Tumor necrosis factor receptor family member RANK mediates osteoclast differentiation and activation induced by osteoprotegerin ligand," Proceedings of the National Academy of Sciences of the United States of America, vol. 96, no. 7, pp. 3540-3545, 1999.

[129] W. J. Boyle, W. S. Simonet, and D. L. Lacey, "Osteoclast differentiation and activation," Nature, vol. 423, no. 6937, pp. 337-342, 2003.

[130] D. Liu, J. K. Xu, L. Figliomeni et al., "Expression of RANKL and OPG mRNA in periodontal disease: possible involvement in bone destruction," International Journal of Molecular Medicine, vol. 11, no. 1, pp. 17-21, 2003.

[131] M. Mogi, N. Ozeki, H. Nakamura, and A. Togari, "Dual roles for NF-kappaB activation in osteoblastic cells by serum deprivation: osteoblastic apoptosis and cell-cycle arrest," Bone, vol. 35, no. 2, pp. 507-516, 2004.

[132] G. N. Belibasakis and N. Bostanci, "Inflammatory and bone remodeling responses to the cytolethal distending toxins," Cells, vol. 3, no. 2, pp. 236-246, 2014.

[133] J.-P. Gorvel and S. Méresse, "Maturation steps of the Salmonellacontaining vacuole," Microbes and Infection, vol. 3, no. 14-15, pp. 1299-1303, 2001.

[134] D. W. Holden, "Trafficking of the Salmonella vacuole in macrophages," Traffic, vol. 3, no. 3, pp. 161-169, 2002.

[135] K. Sandvig, J. Bergan, S. Kavaliauskiene, and T. Skotland, "Lipid requirements for entry of protein toxins into cells," Progress in Lipid Research, vol. 54, pp. 1-13, 2014.

[136] J. S. Bonifacino and R. Rojas, "Retrograde transport from endosomes to the trans-Golgi network," Nature Reviews Molecular Cell Biology, vol. 7, no. 8, pp. 568-579, 2006.

[137] P. De Figueiredo, D. Drecktrah, R. S. Polizotto, N. B. Cole, J. Lippincott-Schwartz, and W. J. Brown, "Phospholipase $A_{2}$ antagonists inhibit constitutive retrograde membrane traffic to the reticulum," Traffic, vol. 1, no. 6, pp. 504-511, 2000.

[138] T. I. Klokk, A. B. D. Lingelem, A.-G. Myrann, and K. Sandvig, "Role of phospholipase $\mathrm{A}_{2}$ in retrograde transport of ricin," Toxins, vol. 3, no. 9, pp. 1203-1219, 2011.

[139] P. U. Mayerhofer, J. P. Cook, J. Wahlman et al., "Ricin A chain insertion into endoplasmic reticulum membranes is triggered by a temperature increase to $37^{\circ} \mathrm{C}$," Journal of Biological Chemistry, vol. 284, no. 15, pp. 10232-10242, 2009.

[140] M. L. Suhan and C. J. Hovde, "Disruption of an internal membrane-spanning region in Shiga toxin 1 reduces cytotoxicity," Infection and Immunity, vol. 66, no. 11, pp. 5252-5259, 1998.

[141] K. A. Bradley, J. Mogridge, M. Mourez, R. J. Collier, and J. A. T. Young, "Identification of the cellular receptor for anthrax toxin," Nature, vol. 414, no. 6860, pp. 225-229, 2001.

[142] K. A. Bradley and J. A. T. Young, "Anthrax toxin receptor proteins," Biochemical Pharmacology, vol. 65, no. 3, pp. 309-314, 2003.

[143] S. Liu, Y. Zhang, B. Hoover, and S. H. Leppla, "The receptors that mediate the direct lethality of anthrax toxin," Toxins (Basel), vol. 5, no. 1, pp. 1-8, 2013. 
[144] M. Martchenko, S.-Y. Jeong, and S. N. Cohen, "Heterodimeric integrin complexes containing $\beta 1$-integrin promote internalization and lethality of anthrax toxin," Proceedings of the National Academy of Sciences of the United States of America, vol. 107, no. 35, pp. 15583-15588, 2010.

[145] H. M. Scobie, G. J. A. Rainey, K. A. Bradley, and J. A. T. Young, "Human capillary morphogenesis protein 2 functions as an anthrax toxin receptor," Proceedings of the National Academy of Sciences of the United States of America, vol. 100, no. 9, pp. 51705174, 2003.

[146] L. Abrami, S. Liu, P. Cosson, S. H. Leppla, and F. G. van der Goot, "Anthrax toxin triggers endocytosis of its receptor via a lipid raft-mediated clathrin-dependent process," Journal of Cell Biology, vol. 160, no. 3, pp. 321-328, 2003.

[147] D. B. Lacy, M. Mourez, A. Fouassier, and R. J. Collier, "Mapping the anthrax protective antigen binding site on the lethal and edema factors," Journal of Biological Chemistry, vol. 277, no. 4, pp. 3006-3010, 2002.

[148] M. Mourez, D. B. Lacy, K. Cunningham et al., "2001: a year of major advances in anthrax toxin research," Trends in Microbiology, vol. 10, no. 6, pp. 287-293, 2002.

[149] M. Kitamura, M. Iwamori, and Y. Nagai, "Interaction between Clostridium botulinum neurotoxin and gangliosides," Biochimica et Biophysica Acta, vol. 628, no. 3, pp. 328-335, 1980.

[150] D. Dressler and F. A. Saberi, "Botulinum toxin: mechanisms of action," European Neurology, vol. 53, no. 1, pp. 3-9, 2005.

[151] Y. Ueno, M. Ohara, T. Kawamoto et al., "Biogenesis of the Actinobacillus actinomycetemcomitans cytolethal distending toxin holotoxin," Infection and Immunity, vol. 74, no. 6, pp. 34803487, 2006.

[152] A. Frisk, M. Lebens, C. Johansson et al., "The role of different protein components from the Haemophilus ducreyi cytolethal distending toxin in the generation of cell toxicity," Microbial Pathogenesis, vol. 30, no. 6, pp. 313-324, 2001.

[153] B. J. Shenker, D. Besack, T. McKay, L. Pankoski, A. Zekavat, and D. R. Demuth, "Actinobacillus actinomycetemcomitans cytolethal distending toxin ( $\mathrm{Cdt}$ ): evidence that the holotoxin is composed of three subunits: CdtA, CdtB, and CdtC, Journal of Immunology, vol. 172, no. 1, pp. 410-417, 2004.

[154] X. Hu and C. E. Stebbins, "Dynamics and assembly of the cytolethal distending toxin," Proteins, vol. 65, no. 4, pp. 843-855, 2006.

[155] L. Guerra, K. Teter, B. N. Lilley et al., "Cellular internalization of cytolethal distending toxin: a new end to a known pathway," Cellular Microbiology, vol. 7, no. 7, pp. 921-934, 2005.

[156] S. Sever, "Dynamin and endocytosis," Current Opinion in Cell Biology, vol. 14, no. 4, pp. 463-467, 2002.

[157] S. Sever, A. B. Muhlberg, and S. L. Schmid, "Impairment of dynamin's GAP domain stimulates receptor-mediated endocytosis receptor-mediated endocytosis," Nature, vol. 398, no. 6727, pp. 481-486, 1999.

[158] A. Gargi, M. Reno, and S. R. Blanke, "Bacterial toxin modulation of the eukaryotic cell cycle: are all cytolethal distending toxins created equally?" Frontiers in Cellular and Infection Microbiology, vol. 2, no. 124, pp. 1-11, 2012.

[159] L. Guerra, K. N. Nemec, S. Massey et al., "A novel mode of translocation for cytolethal distending toxin," Biochimica et Biophysica Acta, vol. 1793, no. 3, pp. 489-495, 2009.

[160] M. Damek-Poprawa, J. Y. Jang, A. Volgina, J. Korostoff, and J. M. DiRienzo, "Localization of Aggregatibacter actinomycetemcomitans cytolethal distending toxin subunits during intoxication of live cells," Infection and Immunity, vol. 80, no. 8, pp. 2761-2770, 2012.

[161] A. Gargi, B. Tamilselvam, B. Powers et al., "Cellular interactions of the cytolethal distending toxins from Escherichia coli and Haemophilus ducreyi," The Journal of Biological Chemistry, vol. 288, no. 11, pp. 7492-7505, 2013.

[162] L. A. McSweeney and L. A. Dreyfus, "Nuclear localization of the Escherichia coli cytolethal distending toxin CdtB subunit," Cellular Microbiology, vol. 6, no. 5, pp. 447-458, 2004.

[163] J. Coburn and J. M. Leong, "Microbiology. Arresting features of bacterial toxins," Science, vol. 290, no. 5490, pp. 287-288, 2000.

[164] C. Comayras, C. Tasca, S. Y. Pérès, B. Ducommun, E. Oswald, and J. De Rycke, "Escherichia coli cytolethal distending toxin blocks the HeLa cell cycle at the G2/M transition by preventing cdc2 protein kinase dephosphorylation and activation," Infection and Immunity, vol. 65, no. 12, pp. 5088-5095, 1997.

[165] J. M. DiRienzo, M. Song, L. S. Y. Wan, and R. P. Ellen, "Kinetics of $\mathrm{KB}$ and HEp-2 cell responses to an invasive, cytolethal distending toxin-producing strain of Actinobacillus actinomycetemcomitans," Oral Microbiology and Immunology, vol. 17, no. 4, pp. 245-251, 2002.

[166] X. Cortes-Bratti, E. Chaves-Olarte, T. Lagergård, and M. Thelestam, "The cytolethal distending toxin from the chancroid bacterium Haemophilus ducreyi induces cell-cycle arrest in the G2 phase," Journal of Clinical Investigation, vol. 103, no. 1, pp. 107-115, 1999.

[167] G. Lépine, S. Caudry, J. M. DiRienzo, and R. P. Ellen, "Epithelial cell invasion by Actinobacillus actinomycetemcomitans strains from restriction fragment-length polymorphism groups associated with juvenile periodontitis or carrier status," Oral Microbiology and Immunology, vol. 13, no. 6, pp. 341-347, 1998.

[168] D. H. Meyer, J. E. Lippmann, and P. M. Fives-Taylor, "Invasion of epithelial cells by Actinobacillus actinomycetemcomitans: a dynamic, multistep process," Infection and Immunity, vol. 64, no. 8 , pp. $2988-2997,1996$.

[169] D. H. Meyer, P. K. Sreenivasan, and P. M. Fives-Taylor, "Evidence for invasion of a human oral cell line by Actinobacillus actinomycetemcomitans," Infection and Immunity, vol. 59, no. 8, pp. 2719-2726, 1991.

[170] E. P. Gilchrist, M. P. Moyer, E. J. Shillitoe, N. Clare, and V. A. Murrah, "Establishment of a human polyclonal oral epithelial cell line," Oral Surgery, Oral Medicine, Oral Pathology, Oral Radiology, and Endodontics, vol. 90, no. 3, pp. 340-347, 2000.

[171] P. Kang, J. Korostoff, A. Volgina, W. Grzesik, and J. M. DiRienzo, "Differential effect of the cytolethal distending toxin of Actinobacillus actinomycetemcomitans on co-cultures of human oral cells," Journal of Medical Microbiology, vol. 54, no. 8, pp. 785794, 2005.

[172] M. Damek-Poprawa, M. Haris, A. Volgina, J. Korostoff, and J. M. DiRienzo, "Cytolethal distending toxin damages the oral epithelium of gingival explants," Journal of Dental Research, vol. 90, no. 7, pp. 874-879, 2011.

[173] M. Alaoui-El-Azher, J. J. Mans, H. V. Baker et al., "Role of the ATM-checkpoint kinase 2 pathway in CDT-mediated apoptosis of gingival epithelial cells," PLoS ONE, vol. 5, no. 7, Article ID e11714, 2010.

[174] A. Nalbant, C. Chen, Y. Wang, and H. H. Zadeh, "Induction of T-cell apoptosis by Actinobacillus actinomycetemcomitans mutants with deletion ltxA and cdtABC genes: possible activity of GroEL-like molecule," Oral Microbiology and Immunology, vol. 18, no. 6, pp. 339-349, 2003. 
[175] J. C. Reed, L. Meister, S. Tanaka et al., "Differential expression of $\mathrm{bcl} 2$ protooncogene in neuroblastoma and other human tumor cell lines of neural origin," Cancer Research, vol. 51, no. 24, pp. 6529-6538, 1991.

[176] T. S. Griffith, T. Brunner, S. M. Fletcher, D. R. Green, and T. A. Ferguson, "Fas ligand-induced apoptosis as a mechanism of immune privilege," Science, vol. 270, no. 5239, pp. 1189-1192, 1995.

[177] M. Ohara, T. Hayashi, Y. Kusunoki, M. Miyauchi, T. Takata, and M. Sugai, "Caspase- 2 and caspase-7 are involved in cytolethal distending toxin-induced apoptosis in Jurkat and MOLT-4 Tcell lines," Infection and Immunity, vol. 72, no. 2, pp. 871-879, 2004.

[178] M. Ohara, T. Hayashi, Y. Kusunoki et al., "Cytolethal distending toxin induces caspase-dependent and -independent cell death in MOLT-4 cells," Infection and Immunity, vol. 76, no. 10, pp. 4783-4791, 2008.

[179] S. D. P. Rabin, J. G. Flitton, and D. R. Demuth, "Aggregatibacter actinomycetemcomitans cytolethal distending toxin induces apoptosis in nonproliferating macrophages by a phosphataseindependent mechanism," Infection and Immunity, vol. 77, no. 8, pp. 3161-3169, 2009.

[180] K. P. S. Fernandes, M. P. A. Mayer, E. S. Ando, A. G. Ulbrich, J. G. P. Amarente-Mendes, and M. Russo, "Inhibition of interferon- $\gamma$-induced nitric oxide production in endotoxinactivated macrophages by cytolethal distending toxin," Oral Microbiology and Immunology, vol. 23, no. 5, pp. 360-366, 2008.

[181] J. D. Anderson, A. J. MacNab, W. R. Gransden, S. M. A. Damm, W. M. Johnson, and H. Lior, "Gastroenteritis and encephalopathy associated with a strain of Escherichia coli 055:K59:H4 that produced a cytolethal distending toxin," Pediatric Infectious Disease Journal, vol. 6, no. 12, pp. 1135-1136, 1987.

[182] M. Ansaruzzaman, M. J. Albert, S. Nahar et al., "Clonal groups of enteropathogenic Escherichia coli isolated in casecontrol studies of diarrhoea in Bangladesh," Journal of Medical Microbiology, vol. 49, no. 2, pp. 177-185, 2000.

[183] H. Karch, P. I. Tarr, and M. Bielaszewska, "Enterohaemorrhagic Escherichia coli in human medicine," International Journal of Medical Microbiology, vol. 295, no. 6-7, pp. 405-418, 2005.

[184] J. I. Dasti, A. M. Tareen, R. Lugert, A. E. Zautner, and U. Groß, "Campylobacter jejuni: a brief overview on pathogenicityassociated factors and disease-mediating mechanisms," International Journal of Medical Microbiology, vol. 300, no. 4, pp. 205211, 2010.

[185] J. G. Fox, A. B. Rogers, M. T. Whary et al., "Gastroenteritis in NF- kappaB -deficient mice is produced with wild-type Camplyobacter jejuni but not with C. jejuni lacking cytolethal distending toxin despite persistent colonization with both strains," Infection and Immunity, vol. 72, no. 2, pp. 1116-1125, 2004.

[186] D. Purdy, C. M. Buswell, A. E. Hodgson, K. McAlpine, I. Henderson, and S. A. Leach, "Characterization of cytolethal distending toxin (CDT) mutants of Campylobacter jejuni," Journal of Medical Microbiology, vol. 49, no. 5, pp. 473-479, 2000.

[187] N. P. Mortensen, P. Schiellerup, N. Boisen et al., "The role of Campylobacter jejuni cytolethal distending toxin in gastroenteritis: toxin detection, antibody production, and clinical outcome," APMIS, vol. 119, no. 9, pp. 626-634, 2011.

[188] D. A. Lewis, M. K. Stevens, J. L. Latimer et al., "Characterization of Haemophilus ducreyi cdtA, cdtB, and cdtC mutants in in vitro and in vivo systems," Infection and Immunity, vol. 69, no. 9, pp. 5626-5634, 2001.

[189] C. Wising, L. Mölne, I.-M. Jonsson, K. Ahlman, and T. Lagergård, "The cytolethal distending toxin of Haemophilus ducreyi aggravates dermal lesions in a rabbit model of chancroid," Microbes and Infection, vol. 7, no. 5-6, pp. 867-874, 2005.

[190] R. S. Young, K. R. Fortney, V. Gelfanova et al., "Expression of cytolethal distending toxin and hemolysin is not required for pustule formation by Haemophilus ducreyi in human volunteers," Infection and Immunity, vol. 69, no. 3, pp. 1938-1942, 2001.

[191] C. H. Åberg, G. Antonoglou, D. Haubek, F. Kwamin, R. Claesson, and A. Johansson, "Cytolethal distending toxin in isolates of Aggregatibacter actinomycetemcomitans from Ghanaian adolescents and association with serotype and disease progression," PLoS ONE, vol. 8, no. 6, Article ID e65781, 2013.

[192] C. H. Åberg, B. Sjödin, L. Lakio, P. J. Pussinen, A. Johansson, and R. Claesson, "Presence of Aggregatibacter actinomycetemcomitans in young individuals: a 16-year clinical and microbiological follow-up study," Journal of Clinical Periodontology, vol. 36, no. 10, pp. 815-822, 2009.

[193] P. Bandhaya, P. Saraithong, K. Likittanasombat, B. Hengprasith, and K. Torrungruang, "Aggregatibacter actinomycetemcomitans serotypes, the JP2 clone and cytolethal distending toxin genes in a Thai population," Journal of Clinical Periodontology, vol. 39, no. 6, pp. 519-525, 2012.

[194] A. S. Fabris, J. M. DiRienzo, M. Wikstrom, and M. P. A. Mayer, "Detection of cytolethal distending toxin activity and cdt genes in Actinobacillus actinomycetemcomitans isolates from geographically diverse populations," Oral Microbiology and Immunology, vol. 17, no. 4, pp. 231-238, 2002.

[195] K. S. Tan, K.-P. Song, and G. Ong, "Cytolethal distending toxin of Actinobacillus actinomycetemcomitans: occurrence and association with periodontal disease," Journal of Periodontal Research, vol. 37, no. 4, pp. 268-272, 2002.

[196] X. Wang, L. Li, M. Yang et al., "Prevalence and distribution of Aggregatibacter actinomycetemcomitans and its $c d t B$ gene in subgingival plaque of Chinese periodontitis patients," $B M C$ Oral Health, vol. 14, no. 37, pp. 1-7, 2014.

[197] R. Yamano, M. Ohara, S. Nishikubo et al., "Prevalence of cytolethal distending toxin production in periodontopathogenic bacteria," Journal of Clinical Microbiology, vol. 41, no. 4, pp. 13911398, 2003.

[198] E. S. Ando, L. A. de-Gennaro, M. Faveri, M. Feres, J. M. DiRienzo, and M. P. A. Mayer, "Immune response to cytolethal distending toxin of Aggregatibacter actinomycetemcomitans in periodontitis patients," Journal of Periodontal Research, vol. 45, no. 4, pp. 471-480, 2010.

[199] A. Johansson, K. Buhlin, R. Koski, and A. Gustafsson, "The immunoreactivity of systemic antibodies to Actinobacillus actinomycetemcomitans and Porphyromonas gingivalis in adult periodontitis," European Journal of Oral Sciences, vol. 113, no. 3, pp. 197-202, 2005.

[200] I. Xynogala, A. Volgina, J. M. Dirienzo, and J. Korostoff, "Evaluation of the humoral immune response to the cytolethal distending toxin of Aggregatibacter actinomycetemcomitans Y4 in subjects with localized aggressive periodontitis," Oral Microbiology and Immunology, vol. 24, no. 2, pp. 116-123, 2009.

[201] H. M. Feder Jr., J. C. Roberts, J. C. Salazar, H. B. Leopold, and O. Toro-Salazar, "HACEK endocarditis in infants and children: two cases and a literature review," Pediatric Infectious Disease Journal, vol. 22, no. 6, pp. 557-562, 2003. 
[202] M. Ohara, M. Miyauchi, K. Tsuruda, T. Takata, and M. Sugai, "Topical application of Aggregatibacter actinomycetemcomitans cytolethal distending toxin induces cell cycle arrest in the rat gingival epithelium in vivo," Journal of Periodontal Research, vol. 46, no. 3, pp. 389-395, 2011.

[203] M. Damek-Poprawa, J. Korostoff, R. Gill, and J. M. Dirienzo, "Cell junction remodeling in gingival tissue exposed to a microbial toxin," Journal of Dental Research, vol. 92, no. 6, pp. 518-523, 2013.

[204] M. Furuse, M. Hata, K. Furuse et al., "Claudin-based tight junctions are crucial for the mammalian epidermal barrier: a lesson from claudin-1-deficient mice," Journal of Cell Biology, vol. 156, no. 6, pp. 1099-1111, 2002.

[205] H. Aberle, H. Schwartz, and R. Kemler, "Cadherin-catenin complex: protein interactions and their implications for cadherin function," Journal of Cellular Biochemistry, vol. 61, no. 4, pp. 514$523,1996$.

[206] B. Baum and M. Georgiou, "Dynamics of adherens junctions in epithelial establishment, maintenance, and remodeling," Journal of Cell Biology, vol. 192, no. 6, pp. 907-917, 2011.

[207] P. Ye, C. C. Chapple, R. K. Kumar, and N. Hunter, "Expression patterns of E-cadherin, involucrin, and connexin gap junction proteins in the lining epithelia of inflamed gingiva," Journal of Pathology, vol. 192, no. 1, pp. 58-66, 2000.

[208] V. Aragon, K. Chao, and L. A. Dreyfus, "Effect of cytolethal distending toxin on F-actin assembly and cell division in Chinese hamster ovary cells," Infection and Immunity, vol. 65, no. 9, pp. 3774-3780, 1997.

[209] J. M. DiRienzo, "Breaking the gingival epithelial barrier: role of the Aggregatibacter actinomycetemcomitans cytolethal distending t oxin in oral infectious disease," Cells, vol. 3, no. 2, pp. 476499, 2014.

[210] B. M. Allos, “Campylobacter jejuni infections: update on emerging issues and trends," Clinical Infectious Diseases, vol. 32, no. 8, pp. 1201-1206, 2001.

[211] G. M. Ruiz-Palacios, "The health burden of Campylobacter infection and the impact of antimicrobial resistance: playing chicken," Clinical Infectious Diseases, vol. 44, no. 5, pp. 701-703, 2007.

[212] Z. Ge, D. B. Schauer, and J. G. Fox, "In vivo virulence properties of bacterial cytolethal-distending toxin," Cellular Microbiology, vol. 10, no. 8, pp. 1599-1607, 2008. 

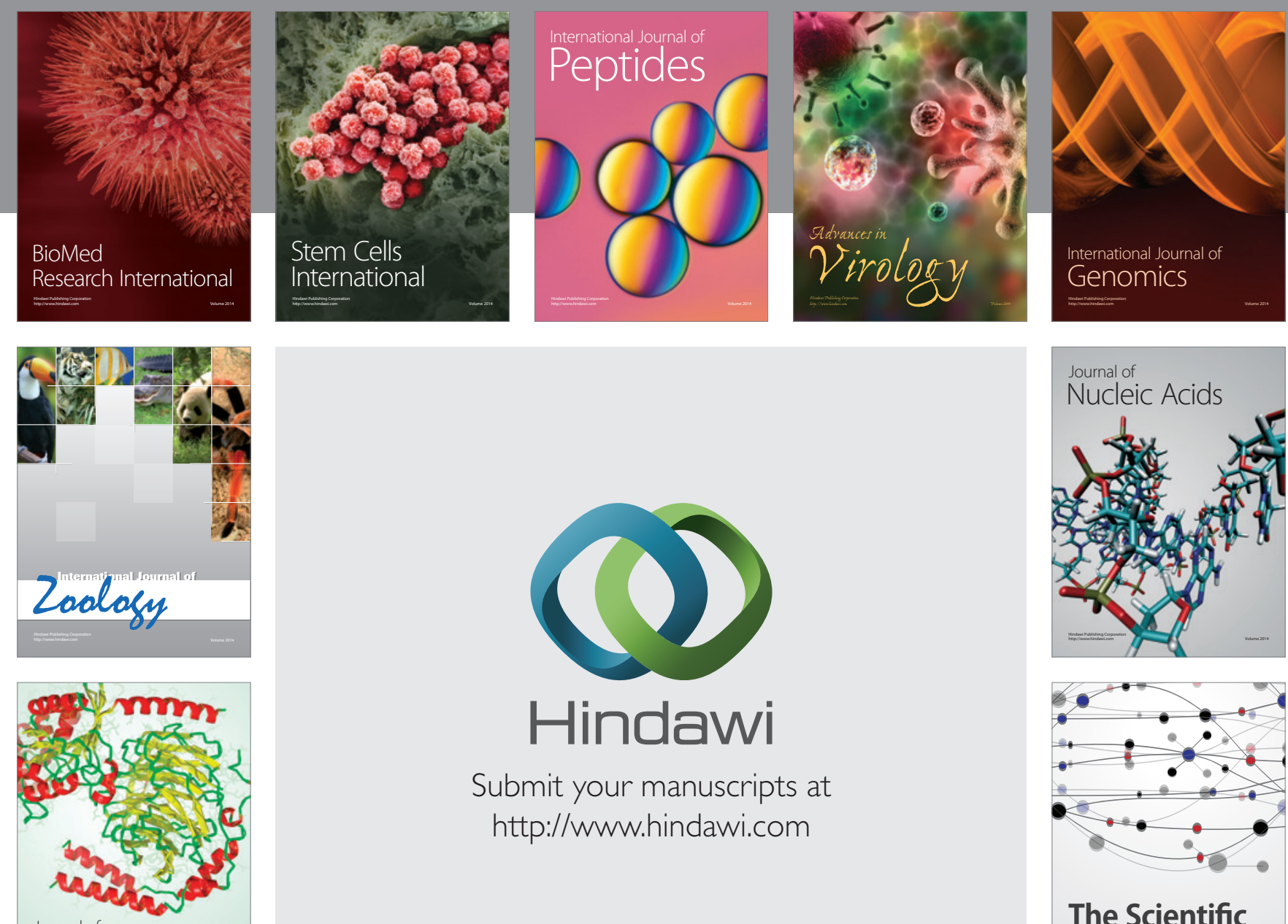

Submit your manuscripts at

http://www.hindawi.com

Journal of
Signal Transduction
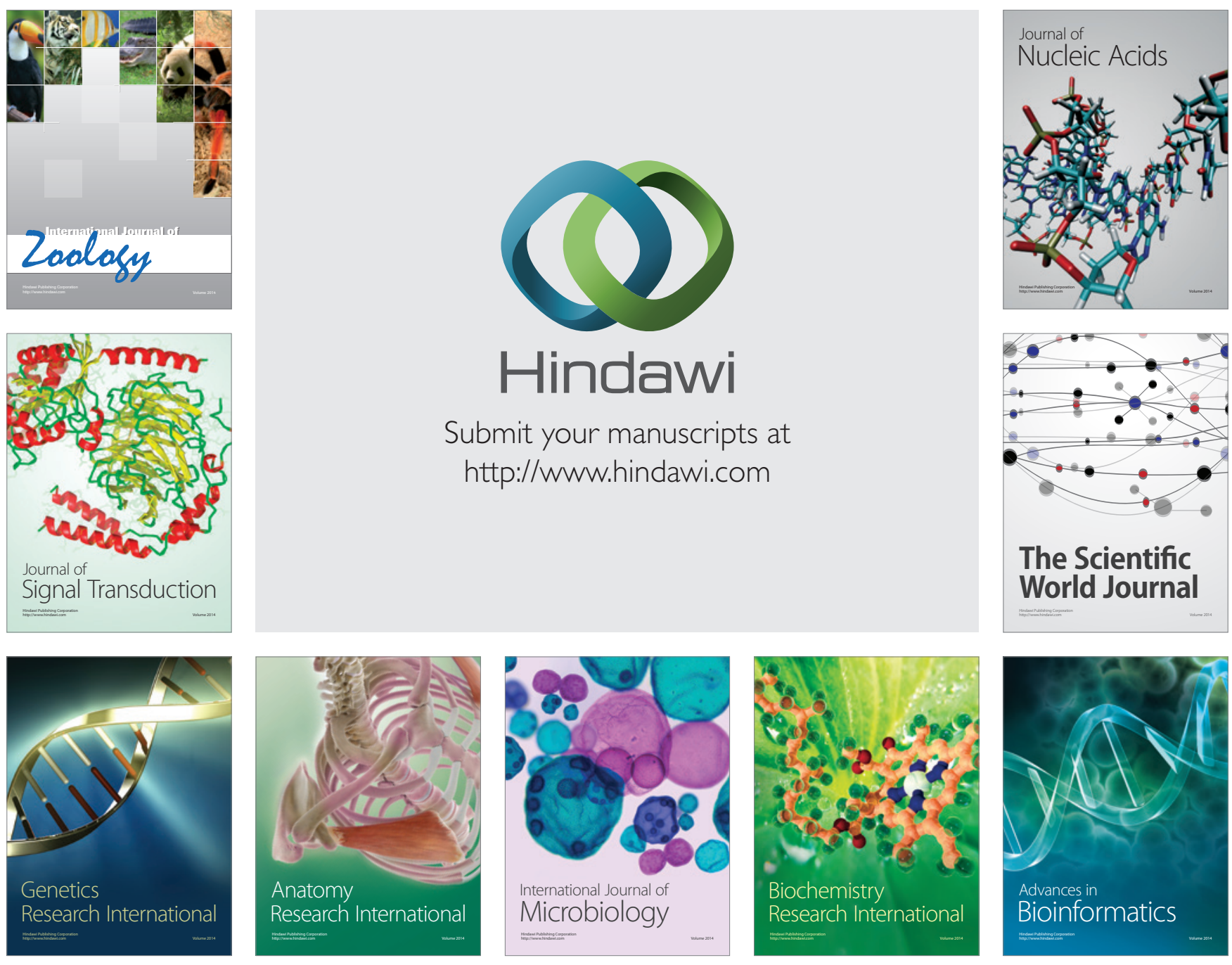

The Scientific World Journal
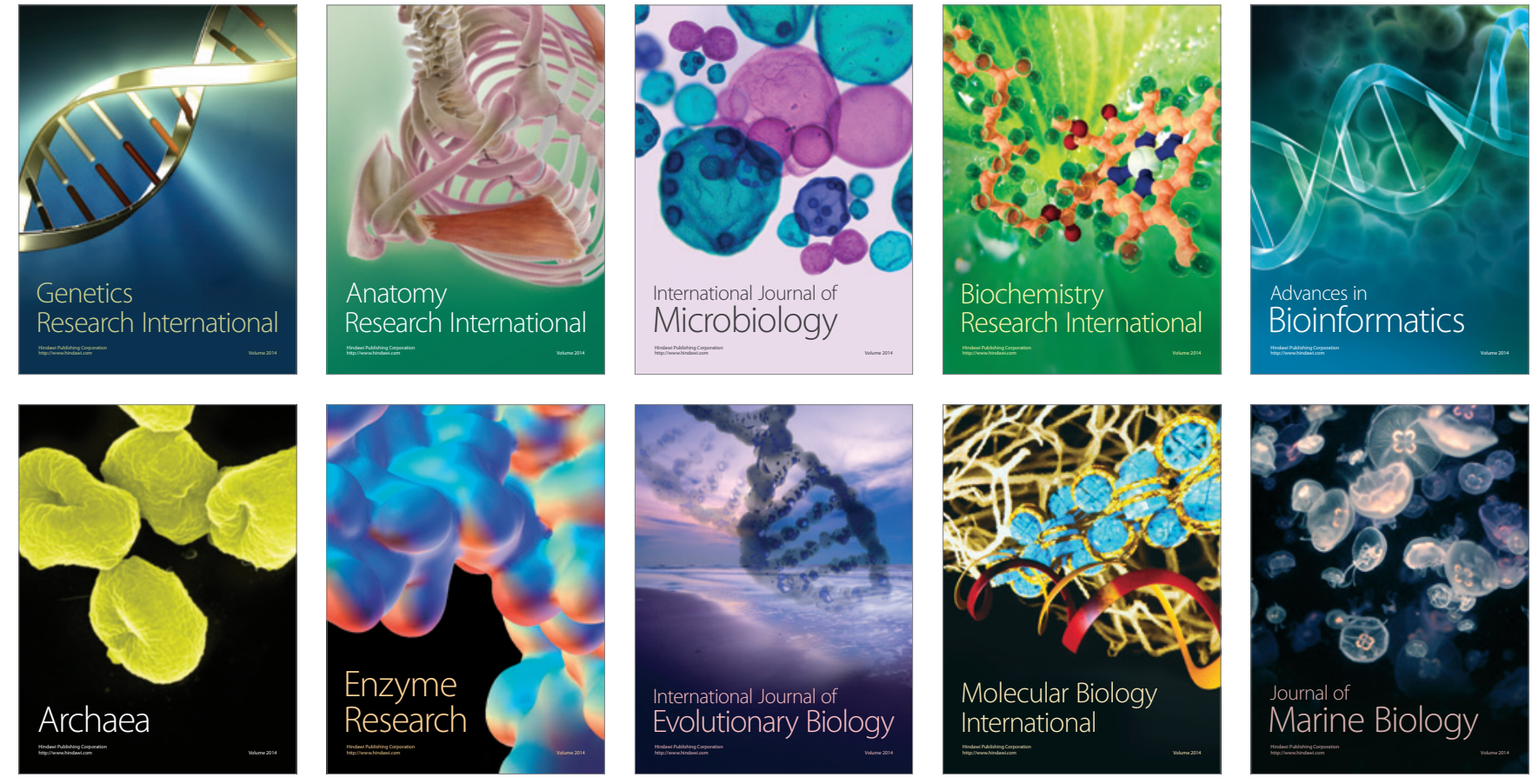